


\section{SUR LA STRUCTURE DES}
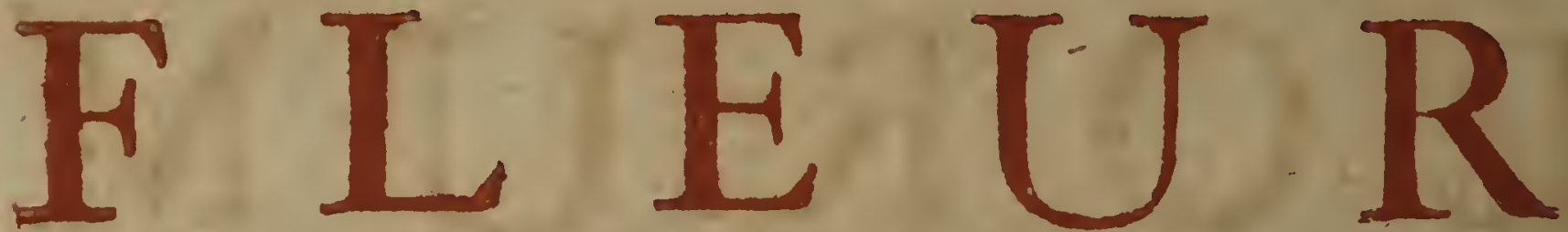

LEURS DIFFERENCES ET L'USAGE DE LEURS PARTIES:

Prononcé a l'Ouverture du Jardin Royal de Paris, le $\mathrm{X}^{\mathrm{e}}$. Jour du mois de Juin 1717 .

\section{L'E T A B L IS S E M E N T de trois nouveanx gemres de}
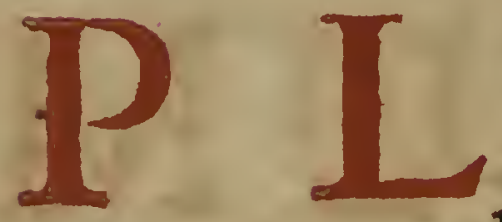

L'AR A L I A S T R U M,
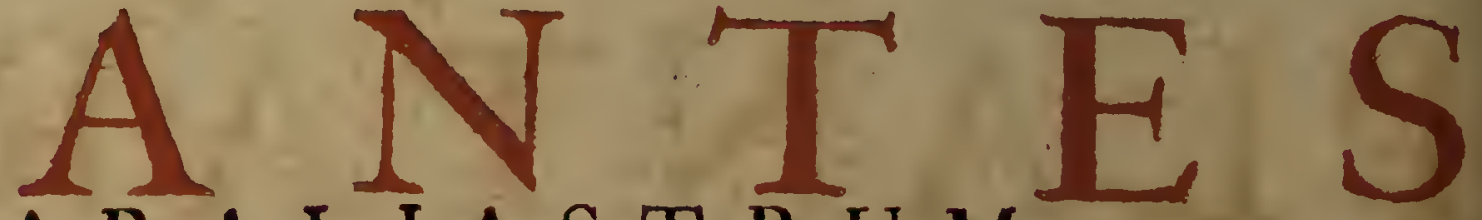

L A S HE R A R D I A,

L A B O E R H A A I A.

Avec la Defcription de deux nowvelles $\mathrm{P}_{\mathrm{L}}$ ant $\mathrm{x}$ rapportées au dernier genre,

\section{Par}

SEBASTIEN VAILLANT, Demonfrateur des Plantes du Fardin Royal à Paris.

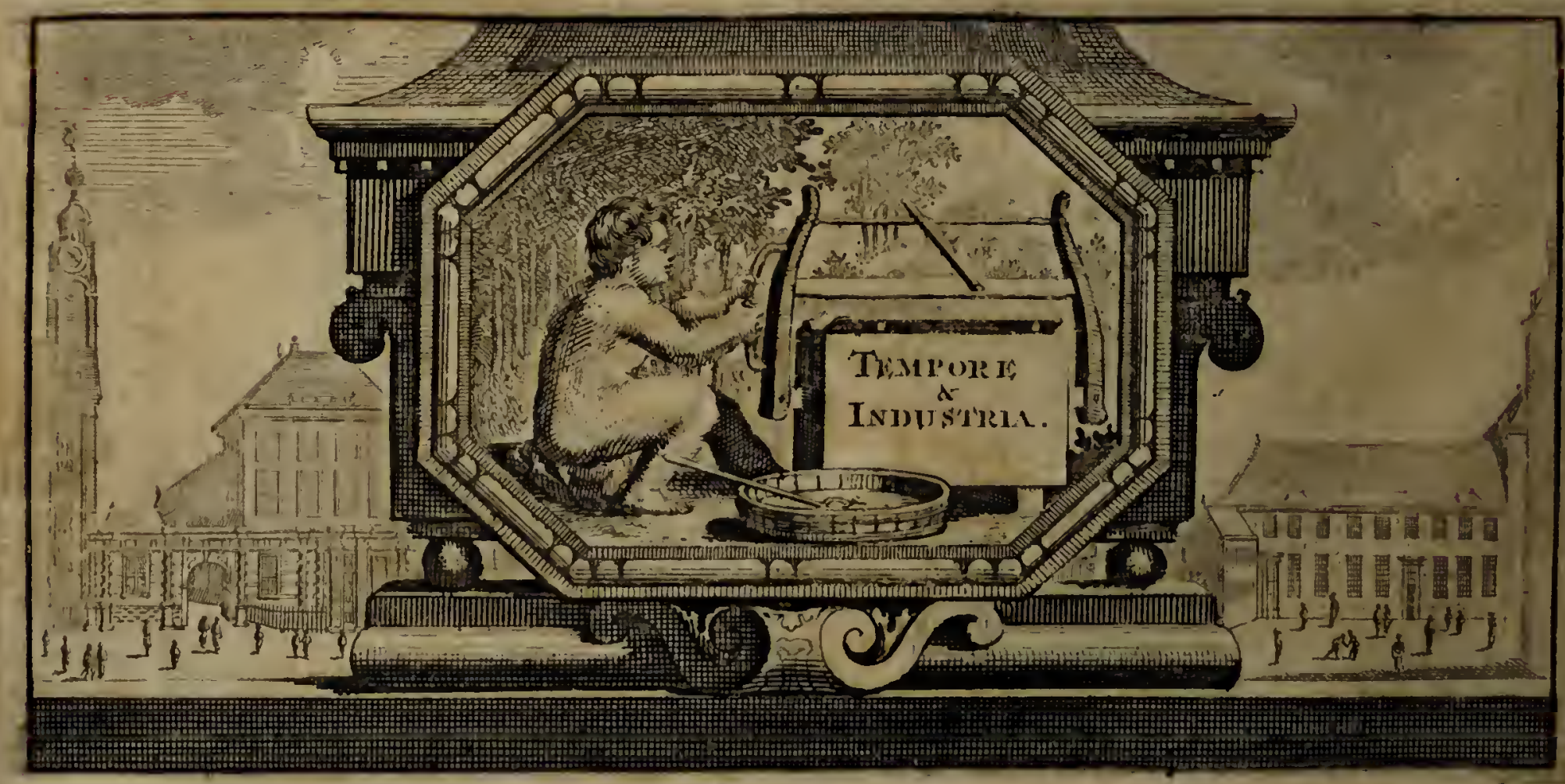

$$
\text { A LEIDE }
$$

Chez PIERRE $V A N D E R A a$, Marchand Libraire, Imprimeur de l'Univerfité $\Theta$ de la Ville. M DCC XVIII 



\section{REI HER BAR IAE S T U D I OS IS}

PETRUS VANDER Aa $S$.

Trtunatô evenit, ut in meas inciderint manus, quas Vobis palam offero, fuper pulchrâ, quam colitis, difciplinâ differtationes: quum enim fingularia plurima, nec dicta Aliis, contineant, atque perfpicuâ enarrent dictione, digniflimas aeltimavi, quae in ufus evulgarentur publicos. Maximé, poftquam confulti fuper his Viri, penes quos facultas de illis judicandi, in eâ me fententiầ confirmaflent, fuoque mihi praeconio Auctores effent, ut ocyus ederentur. Vobis itaque infcribo eafdem, emaculatiores fanê futuras, $f_{1}$ ipfe in Latinum convertiffet, fi ipfe emendaffet, harum Dominus. Sed intellexeram, Virum Celeberrimum haud ita facilem in emittenda fua in publicum, ideoque, fr rogaretur, forte interceffurum. Ergo ne fic quidem, ut apparent alienâ evulgatae curâ , difplicituras vobis crediderim ! fatius quippe arbitror, opus utile juvare publica commoda, quam idem inter manus nimis atque anxiê elegantis Auctoris in omne aevum premi. Immodica fanê elaboratiffimx perfectionis ftudia optima quaeque eripuere Publico. Summifque femper vitium fuit Viris, quod propriis operibus ne meritas quidem laudes tribuere aufi fint, Valete! 
Pag 2

\section{I S C O U R}

Sur la Structure des Fleurs, leurs differences, छo

l'ufage de leurs parties; prononicé a l'ouver-

ture du Fardin Royal de Paris, par $M$.

Vaillant, Demonftrateur des Plan-

tes, le $\mathrm{x}^{\mathrm{c}}$. Four du mois de:

Juin 1717 .

Recrieilli par les Etudians en Botanique.

\section{E S S I E U R S,}

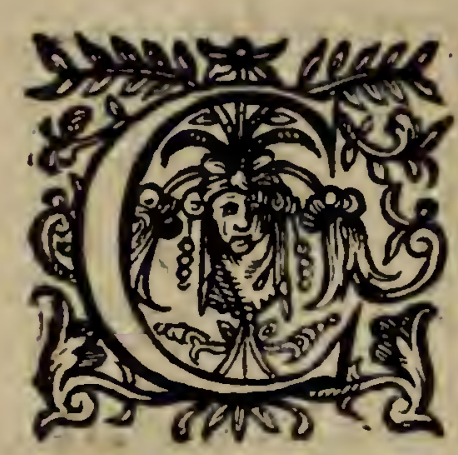

omme entre les parties qui caracterifent les Plantes, celles qu'on appelle Fleurs, Jont, fans contredit, des plus effentielles, il eft: a propos de vous en entretenir d'abord; d'autant plius que tous les Botaniftes ne nous en ont donné que des idées afjez confufes.

Peut étre que le langage dont je me fervirai a ce fujet, Semblera un peu nouveau en. Botanique; mais com-. me il Sera rempli de termes tout a fait convenables a l'ufage des parties que j'ai a exposer, je croi qu'on l'entendra beaucoup mieux que l'ancien, lequel êtant farci:

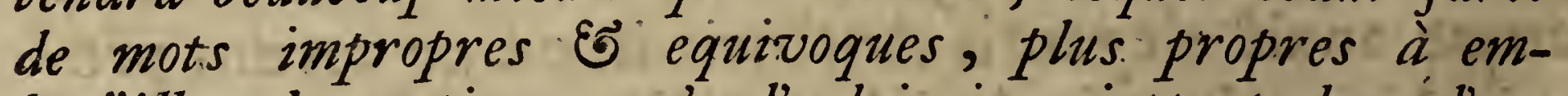
broüiller la matiere, qu'a l'eclaircir, jettent dans l'erreur ceux dont l'imagination encore offufquée, n'a aucune bonne notion des veritablés fonctions de la pluspart. de ces mêmes parties.

Les Fleurs, abjolument, parlant, ne devroient être prifes que pour les organes qui conftituent les differents fexes des. Plantes, puifqu'on trouve quelque fois ces organes nuds, 


\section{$S E R \quad N / O$}

Super fabricâ Florion, borum differentiá, Go uft partium que illos componint, quem habuit, Vir Clarifimus, Sebaftianus Vaillant, Plantarum in Horto Regio Parifino Demonfrator, quum x. Juniz 17 17. Stirpes ibidem demonfirare aupicaretur, prout a Studiofis rei Herbariae exceptus, atque in linguam deinat Latinam versus, babetur.

\section{A U D I T O R E S.}

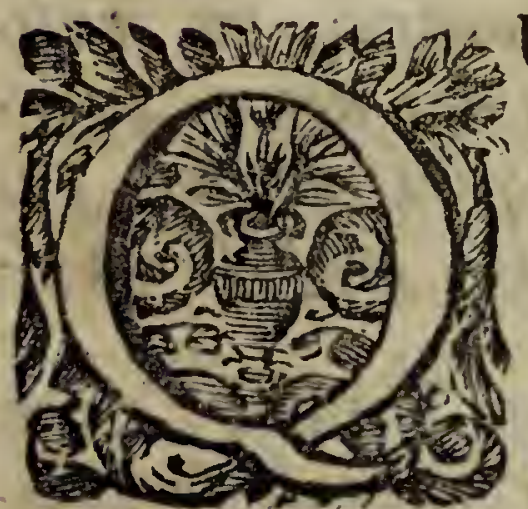

Uoniam inter omnes ftirpium partes, quibus character Plantarum, definitur, illae, quos Flores appellant, maxime earum naturae fingulari conjunctae fpectantur; rationi confentaneum eft fuper his ocyus Vobiscum agere; idque eo quidem magis, quod nemo Botanicorum hactentis illorum ideas, nifi confufe nimium, depictas dederit.

Dictio forte, quâ ad hanc materiem utar, nova fatis in difciplinâ videbitur Herbariâ ; verum tamen, quum referta futura fit vocabulis appofitiffimis ufui partium quem exponendum habeo, longe facilius intellectum iri crediderim recentem hanc, quam Veterem, ufi-tatamque. Enimverô plena ubique haec vocibus impropriis pariter \& ambiguis, quibus profectô longê magis intricatur, quam illuiftratur, argumentum: unde in errorem praecipites dari doleas, quorum intelligentia, tenebris hifce immerfa, nihil veri capit de genuino ufu earundem partium.

Si vera eloqui fas eft, agnofcere oportet, flores pro organis genitalibus, quibus diverfi in plantis conftituuntur fexus:Quippe fpectare licet quandoque nuda haec membra, ut in $T_{y}$ -

$$
A_{2} \quad p b A
$$


comme dans la Typhe ou Maffe d'eau a; le Limnopeuce Cordi b ; le Potamogeito affinis Graminifolia aquatica, Raiz; " c danis quelques efpeces de Frefnes E̋c. Et que les tuniques ou petales aui les environnent immediatement dans les plantes ou ils fe manifefent, ne font defineés quia Les couvrir \&o a les defendre. Mais comme ces tumiques font ordinairement ce quitl $y$ a de plus bean Eु de plus apparent dans le composé auquel on a donné le nom de Fleur, छs que c'eft precifement là que fe borne la curiofité, l'amour \&s l'admiration de prefgue tout le genre bumain qui ne fait mulle attention an refie dont il ignore Eే le nom \&ु l'usage; ce font ces tuniques que par preciput, jappellerai Fleurs, de quelque ftructure, \& de quelquie couleur quielles puifent étre, foit quielles entourent les organes des deux fexes reünis, Joit quielles ne contiennent que ceux de l'un ou de l'autre, ou feulement quelques parties dépendantes de lun des deux, pourveî toute fois que la figure de ces tuniques ne foit pas la méme que celle des feruilles. de la plante, Supposé quielle en porte.

Sur ce principe, je niomme Fleurs nuës ou Fauffes Fleurs, ou fi lion vent, Fleurs effleurées, les organes de la géneration qui font demuéz de petales, Es vraies-Fleurs, cenx qui en font reveftus.

L'on voit par ce premier debut, que je sape entierement les Fleurs à Etamines ou ces captienfes Fleurs fans fleur, race maudite, qui femble $n^{2}$ avoir été créee on inventée que pour en impofer aux plus. babiles, E̛ défoler abfolument les jeunes Botaniftes, lesquels en étant debarafez, fe trouvent d'abord en état d'entrer téte levée dans le vafte empire de Flore, E̋ de decider en Maitres fur toutes les parties des Fleurs.

Si celui de tous les Autbeurs qui a le phus domné dans le Fleurisme, s'y étoit pris de la forte, il n'auroit pas avancé qu'il eft bien difficile de determiner en plufieurs

- Typha palufrris, b Hiftor. 150, c Hifr. ., 190. a Petalar. 


\section{STR UCTURE DES FLEURS, \&c:}

phâ paluftri Limnopence Cordi, potamogeitoni affini graminifoliâ Raji, in fpeciebus nonnullis Fraxini, aliisque. Ubi autem petala ambiunt Flores quam arctiffimê, quod fieri cernitur in Plantis bracteato donatis flore, tum verô quam liquidiffimê apparet, haecce florum foliola dicta tantum iis tegendis nata effe atque defendendis. Quum verô bracteae hae pulcherrimam, atque fpectabilem prae caeteris, partem floris vulgô appellati abfolvant, atque in ejus contemplatione ftudium, amor, \& admiratio haereat hominum, evenit eâ re, ut nullam habuerint rationem caeterarum partium, quae flori componendo ferviunt: taedebat quippe animum iis advertere, quarum verum nomen, unâ cum praeclaro ufu, penitus ignorabant. Has itaque tunicas ego flores appellabo, ob excellentiam gentilitii ttemmatis, dotalisque beneficii, quâcunque demum fabricâ conftructạe fuerint, quocunque colore fplendeant, five amplectantur genitalia utriufque fexus uniti, five comprehendant alterutrum tantum, five denique circumcingant modô partes quasdam pertinentes ad aliquem horum fexuum. Eâ tamen lege, ne figura petalorum eadem lit figurae foliorum plantae ejufdem, fi ea fert. Hâc ego ratione Flores nudos, aut Jpurios flores, appellabo, aut \& Flores imperfectos, fi ita velis, genitalia ftirpium nuda petalis; fed veros fores dicam organa generationis plantae, quae petalis inveftita fpectantur.

Nonne intelligitis ex ipfo hocce exordio, me evertere funditus flores ftamineos, aut florés iftos dolofos fine floribus? heu ftirpem invifam! nec alio natam, cultamve, fato, nifi ut peritiffimo cuique imponat, Juniores verô Botanicorum penitus praecipitet, deftruatque. Hâc verô ipfâ fi liberi fint, aptos natos cernas, qui fublimi incedentes vertice per vafta Florae imperia, auctoritate Magiftrorum fuam apertê fententiam dicant fuper omnibus florum partibus.

Quod fi Celeberrimus Vir, qui inter omnes Auctores maximê excoluit Florum Rempublicam atque ornavit, hancce inftitiffet viam, longê abfuiffet fane a fermone, quo declarat; Saepenumerô arduam valde baberi defignationem 
rencontres ce qu'il faut appeller les feuilles (ou pour eviter l'ambiguité, les petales) de la fleur, Eु ce qu'il faut nommer le calice de la méme fleur, Eீ il n'auroit pas: fi fouvent pris celui-ci pour celle-là, छే encore plus fouvent. celle-là pour celui-ci.

De la maniere que je viens de definir la vraye-Fleur: on entend bien qu'elle doit eftre épanoüie; car lors qu'elle n'eft encore qu'en bouton, non feulement fes tuniques entourent immediatement les organes de la génération. mais elles les cachent auffi fi exactement qu'en cet eftat on la peut regarder comme leur lict nuptial, puisque ce n'eft ordinairement qu'aprés qu'ils ont confommé leur mariage, quielle leur permet de fe montrer: on fi elle s'entrouvre quelque peu pendant qu'ils en font aux prifes, elle ne s'epanoüit tres-parfaitement que lors. quils fe font quittez. Le contraire arrive aux Fleurs qui ne contiennent qu'un Jexe, E̋ la raifon en eft évidente. Mais sil arrive que fur un même pied de plante, il fe rencontre des Fleurs qui n'entourent que des. organes feminins, Es d'autres ou fe trouvent les deux. fexes: la tenfion ou le gonflement des organes mafoulins de celle-ci, fe fait $f i$ fubitement, que les lobes diu bouton, cedant a leur impetuofité, s'ecartent ça छॄ là avec une celerité furprenante. Dans cet inftant, ces. fougueux qui femblent ne cliercher qu'a Satisfaire leurs: violents tranfports, ne fe fentent pas pluftôt libres, que faifant brufquement une décbarge générale, un. tourbillon de pouffiere qui fe repand, porte partout la fecondité ; E⿱ par une étrange cataftrophe ils fe trouvent tellement épuifez, que dans lé méme inftant quils donnent la vie, ils se procurent une mort foudaine: 
earum in fore partium, quas pro veris ejus petalis fas fit agnofcere, atque quum curatiffimê illa diftinguere ab iis, quae calicem ejusdem efficiunt. Eâdem certe operâ evitaffet errores, quos frequenter commifit, florem pro calice fumendo, \& frequentius adhuic calicem accipiendo vice floris.

Neque Vos fugit, ex dictis modô de definitione, Floris veri, fequi, requiri, ut bracteae ejus expanfae fint: quamdiu enim gemmae modô fpeciem gerit, tunicae ejus haud tantum cingunt arctê \& tangunt ejus genitalia ; fed \& abfcondunt eadem adeô quidem follicitê, ut hâcce rerum facie thori genialis munere fungi easdem videas. Neque enim plerunque permittunt prius iisdem, ut fefe aëri aperto commitcant, feque oftentent, nifi confummato demum conjugio per lufus genitales. Quod $f_{1}$ quandoque paululum aperuerint ftricta fua vincula, dum in mutuis adhuc haerent amplexibus, fanê non videbis tam€n perfectê expanfa petala, nifi poftquam abfoluto demum conjugali opere dulces complexus laxaverint.

Contraria autem, accidere obfervo is floribus, qui unius modô fexus diftincta continent genitalia: Nec obfcura rei ratio. Quoties autem acciderit, ut in eâdem ftirpe flores gerantur fimul, quorum hi focminina tantum, illi autem mafculina \& foeminina conjuncta, organa cingunt, arrectio, tumorque, organorum mafculinorum in hifce tam fubitố contingit, ut lobuli gemmae flofculofae cedânt illorum impetui, atque hinc inde femet expandant mirabili mehercle velocitate. Etenim eodem hocce momento libidinofa haec ingenia nihil ardentius cogitant, nifi ut violentos luxuriei affectus expleant, neque citius libera fe, \& expedita, experiuntur; quin extemplo quam violentiffimê foecundam explodant, omnemque uno impetu ejaculentur, genituram, diffựâ nimirum pulverulentâ nubeculâ fpärgente quâquâverfum foecundationem arvi gênitalis. Verum, quam rarâ, quam mirâ, cataftrophe! ipfo hoc foecundandi ardore adeô femet exhaufta dolent, ut "ipfo ; quo prolem vitâ donant, momento fibimet mortem parent praefentifimam!

Neque 
Cen'efi pas encore là que fe termine la fcene. A peine ce jeu a-t-il ceffé, que les levres ou lobes de la fleur fe raprocbant l'un de l'autre, avec la méme vitelfe qu'ils s'en étoient écartéz, hii font reprendre fa premiere forme; Et on auroit peine à comprendre, fi l'on ne l'avoit veñ, quelle ent fouffert la mondre violence, ou fli l'on en voïoit encore des marques certaines par les chetives carcafjes de ces vaillants Champions qui la lui ontfaite, \&5 qui reftent quelque tems arborées fur fon faite, ou comme autant de girouettes, elles fervent de joüet aux Zephyres.

Tout cette mechanique re peut aifement remarquer Jur la Parietaire, a libeure du Berger, c'et à dire le matin, temps ou les differents fexes des plantes prennent ordinairement leurs ébats. Et fices Fleurs ne vouloient pas agir de gré pendant quion les obferve', on peut les $y$ forcer en les aiguillonnent doucement avec la pointe d'une épingle; car pour le peu quion en fouleve un des lobes quand elles ont pour ainfi dire, l'age competent, les bampes ou filets des étamines, d'arcuez ou cambrez quils font, venant a fe dreffer comme par un effort violent, on déconvre aufli-tôt ce qui se paffe de plus pariticulier dans cette espece d'exercice amoureux.

Il s'en faut bien que les étamines des plantes qui ne portent que des fleurs ou les deux fexes font reunis, n'agifent avec tant de precipitation Eु de vigueur. Dans le plus grand nombre, leur action ef prefque infenflble; mais il eft a prefumer qne plus elle eft lente, plus lonigue eft la durée de leurs innocents plaifirs. Ce n'eft pas quion en voit qui, fur certaines plantes, tantque la fleur fublifte, domnent encore an moindre attouchement, des fignes de vie bien marquées. Telles font par exiemple; les étamines du Figuier d'Tnde ${ }^{2}$; celles d'Helian. themum Esc.

a) Opuntia: 
Neque vel hîc tamen Scena clauditur. Quid ergo? Vix venereus hic ludus abfolutus eft, quin ilicô florum labia, aut lobuli, ad fe invicem accedant eodem quidem, quo â fe mutuô recefferant, celeritatis impetu, veteremque ita formam ftatim renovent. Ita quidem, ut difficillimum foret credere, flores hofce ullam vim palfos effe, nifi vel ipfe actum hunc vidiffet oculus, vel adhuc cerneret caduca fceleta magnanimorum heroum, qui hanc pugnaverunt pugnam: clara quippe haec geftae fortiter rei monumenta fuperfunt aliquamdiu erecta in campo conflictus, aut Apluftrium inftar Jocularios experiuntur lufus volitantis $\mathrm{Ze}$ phyri.

Apparatum huncce artificiofum facilêfpectare datur in parietariâ. Sed accedas oportet horâ facrâ Veneri! Aurora eft, quae favet \& adfpirat diverforum in plantis fexuum voluptatibus, congreffibufque; ubi verô agere forte renuunt fatis oportunê ex voto Tuo obfervantis, cogere vel fic poteris, aciculae apice leniter modô ftimules. Si enim matura jam hifce aetas lufibus, opus tantum erit quam blandiffimê unum elevare lobulorum, ftatimque fpectaculo quam jucundiffimo oblectaberis. filamenta quippe, vel manubria, ftaminum ex arcuato hactenus incurvoque flexu in erectum arriguntur fitum, ut vi acta violentâ, tumque liquichô fpectatur fingulare quidque \& tectum, quod in exercitio hocce peragitur venereo.

Multum abeft profectô, ut ftamina plantarum, quae flores ferunt, in quibus ambo fexus uniti funt, agant tam praecipiti impetu, tantove cum vigore. Imô verô plerifque harum actio haec fenfu vix percipitur; credibile interim, quô lentiores his, eô durabiles magis, effe innocuas voluptates. Intereâ tamen in nonnullis videre eft plantis, quod floribus earum adhuc fuperflitibus, figna appareant vitae clara ad attactum vel minimum. Experiri poteritis in ftaminibus Opuntiae, Helianthemi, \& aliis. 
Les organes qui confituent les differents fexes des plantes, font deux principaux. Sçavoir les Itamines Es les Ovaires. Les Etamines quej'appelle organes mafculins \& que le celebre Autbeur des Infiututions de Botanique, regarde comme les parties les plus viles E les plus abjectes dans les végetaux; quoi qu'elles foient veritablement des phus nobles: puifqu'clles repiondent a celles qui dans les majles des Animaux fervent a la multiplication de l'ejpece; C'elles-là, dis-je, font compofées de teftes ES de queûés, ou fil l'on veut. s'cutenir anx termes ordinaires, de fommets E़ de filets.

Ces teftes, qu' a jufte titre, on peut appeller tefticules, non Jeulement parce qu'elles en ont fouvent la figure, mais aufip parce qu'en effet elles en font l'office, font, dans toutes lesplantes complettes, de doubles cartouches ou des cap fules membraneufes, qui effentiellement ont deux loges pleines de poufieres, dont les granules prennent ordinairement dans chaque efpece de plante une forme déterminée, comme l'ont obfervé $M^{\circ}$. Grew, Malpigbi, Tournefort, Eg aprés eux, l'Autbeur des obfervations fur la ftructure \& l'ufage des principales parties des fleurs. Memoires de l'Ac. R. des Sc. ann. I 7 I I. p. 2.IO.

Les queiës ou fliets, qui fervent d'attaches E़ des fupports aux teficules, Es qui ne foni proprement que les gaines de beurs vaiffeaux jpermatiques, font ou fimples, comme dans les plantes Graminées, les Cyperacées, les Cruciferes, les Umbelliferes $\overparen{G}$ autres; oubien elles font branchuës, comme dans le Ricin, le Laurier Ëc. Elles font diftinctes Ë Jeparées les unes des antres dans les. fieurs des finfittes plantes; mais dans certaines, comme font celles de la plujpart des Malvacées, des Cucurbitacées, des Legumineufes Eீc. on les trouve fi intimement foudées enfembles, qu'elles ne font qiin feul corps, D'ou eft venu que $M$. Tournefort a pris les Etamines du Houx-frelon, a pour la fleur méme, Es la veritable fleur pour un calice, EG qu'il u'a pas reconnu que ce quil appelle tuiau piramidal doils les plantes Malvacées; tuiau frangé dans l'Azedarach, gaine, dans le Rapuntium, a. Rufcus. 
Organa, quae diverfos plantarum fexus conftituunt, duo primaria habentur ; ftamina fcilicet, \& Ovaria.

Stamina, quae mafcula voco organa, quaeque Clariffimus Inftitutionum Rei herbariae Auctor habet partes viliffimas abjectiffimafque plantarum, funt tamen verê nobiliffimae: utpote fimillimae atque eaedem iis, quae in maribus animalium multiplicandae ferviunt proli. Componuntur \& haec capitulis \& caudis, aut fi vulgatiora amas potius vocabula apices habent \& filamenta.

Capitula haec, quae vero titulo appelles Tefticulos, non modô ob apparentem faepe in illis horum figuram, fed \& quoniam reverâ eorum funguntur officio, conftant, in completis quibufque plantis, loculis geminis, vel capfulis membranaceis, quae certê habent binos receffus pulvere plenos, cujus granula ut plurimum in quâlibet plantarum: fpecie formam affumunt definitam ; ut obfervarunt VIRI EGREGII, GREW , MALPIGHI, TOURNEFORT, atque poft Eofdem Mem. de l'Ac. R. des Scienc. I7Ir.p. 2 ro. Auctor obfervatorum fiuper fructura छु ufu praecipuarum florum partium.

Candae vel filament a, quae ligandis,fuftinendifque, ferviunt tefticulis, quaeque propriê funt vaginae vaforum fpermaticorum ad tefticulos pertinentium, funt vel fimplicia, ut in plantis Gramineis, Cyperaceis, Cruciferis, \&5 Umbelliferis, aliifque ; aut brachiata apparent, ut in Ricino, Lauroque, \&c. haec quidem diftincta funt, \& feparata â fe mutuô in floribus harum ftirpium; at in aliis, ut plerifque Malvaceis, Cucurbitaceis, Legumino/is, \&c. reperiuntur adeô unita \& conglutinata fimul, ut unum modô efficiant corpus. Unde accidit, ut praeclarus Tournefort acceperit ftamina $R u / c i$ pro flore, florem autem verum ejufdem pro calice; utque non agnoverit id, quod tubum vocat pyramidalem in Malvaceis lobum circinnatum in $A$ zedarach, vaginam in Rapuntio, Les- 


\section{2

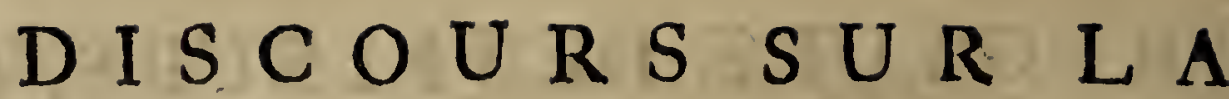

dans les plantes Legumineufes, dans celles à fleurons, dans celles a demi-fleurons, Eु dans les radiées; il ne s'eft pas apperceú, dis-je, que ce qu'il appelle tantôt tuyau, tantôt gaine, n'eft autre chofe que ces queiüs parfaitement jointes Ë intimement unies: accident qui leur eft commun avec les petales de quelques fleurs, qui pour être d'une confiffence charmie \&ु fucculente, ou qui eftant trop comprimez les uns contre les autres dans le calice, fe collent fi bien enfemble qu'ils forment des fleurs monopetales au lieu de polypetales.

L'endroit d'ou les organes mafculins tirent leur origine, n'eft pas toújours le méme dans toutes fortes de fleurs. Ordinairement c'eft de labafe de l'Embrion du fruit lors qu'il eft contenu dans la fleur, foit qu'elle ait plufleurs petales ou qu'elle n'en ait quiun, pourveî que les decoupures de celui-ci s'etendent jufque vers fon centre. Quelquesfois aufi, ces organes partent des reins de l'Embrion, comme dans le Grand Nenufar-blanc. ${ }^{2}$ Si la fleur porte fur l'Embrion, qu'elle foit a calice $\mathfrak{G}$ polypetale, ces mémes organes fortent, ou de la tefte de l'Embrion, ou de l'ongle des petales, ou des espaces vuides qu'ils laiffent entr'-eux ; ou enfin de la furface interne de la partie du cálice qui couronne l, Embrion.

Mais quand la fleur eft d'une feule piece decoupée peu profondement, foit qu' elle contierine l'Embrion ou que l'Embrion la foutienne; ces organes naiffent prefque touijours desparois interieurs de la fleur; Eु je ne Ş̧ache pas qu'ils s'ecartent de cetteregle, fice n'eft au Cabaret bu ouls forment un collier fous le pavillon de la trompe, ainfi que dans l'Arrftoloche Eธ au defus des Ovaires des Pieds de veau ' ${ }^{2}$ 'Europe; mais les fleurs de ces deux derniers genres font entieres \&ु fans lobes. A l'égard des fleurs quine font faites que pour contenir les feulsorganes mafculins, on conçoit afe z que ces organes gle peuvent être attachez que dans la concavité de ces fleurs.

Comme les queniës des tefticules tiennent tout a fait de la nature des petales, il arrive fort fouvent que dans quelques eppeces de certains genres a fleurs polypetales, elles fe traveftifent en petales méme pour former ces agréables monftres a Nymphaca alba major. b Afarum. c Arum. 
guminofis plantis, flofculofis, femifofculofis, \& radiat is, non animadvertit, inquam, id, quod Illi dicitur nunc $T u$ bus, nunc Vagina, nihil aliud effe, quam caudas perfectê junctas, intimêque unitas: Id quod iis certê commune accidit petalis quorundam florum, quae, quod succulentâ conftituantur carnofâque materiê, aut compreffa nimis fint ad fe invicem in ipfo calice, tam arctê conglutinantur inter fe, ut polypetalorum loco flores forment monopetalos.

Non femper idem locus in omnibus florum fpeciebus habetur, unde originem nanfcifcuntur fuam mafculina organa. frequentiffimê a vafis Embryonis fructus, quoties intra florem ille continetur, five polypetalos, five monopetalus fit, fed cujus fegmenta ufque ad centrum ejus fe porrigunt. Eft \& ubi organa haec oriuntur de Lumbis Embryonis, ut in Nymphaeà albâ majore obtinet. Si flos E.mbryoni innafcitur, calicemque poffidet, \& plura habet petala, eadem organa nafcuntur vel ex capite Embryonis, aut ex ungue petalorum, vel ex fpatiolis vacuis intra petala relictis, aut denique à fuperficie internâ partis illius calicis, quae Embryonem coronat.

Quando verô flos monopetalus parum profundê fectus, fue Embryonem contineat, five Embryo eum fuftineat, organa haec fere femper a parietibus internis floris; neque ab hac ea lege recedere novi; nifi Afar um exceperis, in quo formant orbiculum collaris inftar fub latiori inferiorique parte Tubae, ut \& in Arifolocisia, \& fupra ovaria Ari Europaei: fed binis hifce poltremis flores integri abfque lobis: quod tandem attinet ad flores, qui nati modô funt continendis folis mafculinis organis, fatis intelligitur, haecce organa affigi haud polle nifi cavitati ipfius floris.

Quemadmodum caudae tefticulorum verê referunt petalorum naturam, faepe inde evenit, ut in quibufdam certorum generum fpeciebus florum polypetalorum transformentur in petala, ipfa ut amabilia forment monftra, quae

$$
\text { B } 3 \text { tantâ }
$$




\section{If

qu'on ćleve avec tant de foin fous le nom de fleurs doubles \& parmi lefquelles on ne rencontre que peu ou point du tout de tefticules: ces marâtres les devorant, pour ainf dire des le berceau, en s'appropriant toute leur nourrituire.

Mais ces gloutonnes n'en demeurent pas là. Egalement ennemies de tout fexe, apres seêtre défaites de l'un, elles attaquent aufjitôt l'autre; E⿱乛龰 l'affamant peu à peu, le font enfin mourir en langueur. De là vient que fes femences avortent छ̧ quil eft rare d'en tronver de bonnes dans les infortunéz fruits de ces fuperbes fleurs.

Les Ovaires, que Malpighi nomme Matrices, Eु que l'Autheur des Infitutions de Botanique E⿹ Jes Partifans appellent a tort où a traver's, tantôt piftiles E̊ tantót calices, font les organes femininus des plantes, L'ufage en eft trop connue pour. m'y arrêtter, Es leur's figures trop divor fes pour en faire ici la defcription. Il fuffira de dire, que les femences qui font de veritables cufs, s'y nourriffent jufqu' leur parfaite maturité, ES de Vous avertir que je divife ces organes en panfe छే en coû, ou fl'on veut, en corps Eే en trompes.

Le corps ou la panfe, quii eft la partie inferieure de l'ovaire, bien loin détre toijjours renformée dans la feur, comme par exemple, dans les plantés cruciferes, n'en eft fonvent gue le fupport, comme dans les Pomiferes, dans les Umbelliferes, dans la plus part des Liliacées, des Cucurbitacées Eூc. Au lieu que les trompes qui la couronnent Eु laterminent, en quelque endroit quielle foit placée, ne manquent jamais d'être contenues dans la fleur. Prenve évidente que la fleur eft uniquement faite pour la confervation des organes tant de l'un quie de l'autre fexe. ES mullement pour la préparation des fucs qui doivent fervir de premiere nourriture a l'embrion du fruit, qui n'en tire que de fon fupport ou pedicule qui eft auffi celui de touic la mafe de la fleur.

Pour revenir anx trompes qu'avant E depuis Malpighi perfonne ne s'eft avifé de bien diftinguer de la panfe de liovai$r e$, Ë quion ne nous de fugne de fois à autres que fous des noms 


\section{STRUC'TURE DES FLEURS, \&c.}

tantâ educantur curâ titulo florum plenorum; in quibus rarô vel nunquam tefticalos videre licet. Injuftae quippe hae crudelesque novercae ab iplis raptos cunis devorant cosdem, fibique rapiunt avidae omne illorum pabulum.

Neque tamen voraces hae vel fic quiefcunt : imô verô aequê inimicae cuicunque demum fexui, poftquam uni jam exitiales factae, mox alium pariter aggrediuntur, lentâque fenfim fame confumentes mori denique prae languore cogunt. Hinc femina horum infoecunda abortiunt, rarôque fit, ut frugifera reperias inter malê fortunatos fuperbientium florum horumce fructus.

Ovaria Malpighio dictae Matrices, quaeque Auctor inftitutionum rei $\frac{5}{1}$ erbariae, Ejusque lequaces, rectê vel fecus, modô Piftilla, modo appellant Calices, organa funt Plantarum foeminina. Ufus horum innotuit nimis, quam me ut remoretur, nimisque Variae reperiuntur figurae eorundem, quam ut defcribantur hîc loci; fufficict dixiffe, femina, quae vera funt ova, ibi nutriri in maturitatem perfectam ufque, Vosque monuiffe me diridere organa haec in $V$ entrem Collumque, aut, fi placet, in Corpus \& Tubas.

Corpus vel $V$ enter, quae inferior ovarii pars, nequaquam femper inclufa flori habetur, ut exempli gratit in plantis Cruciferis; contrâ verô faepe fuftentaculum modô floris apparet, ut in Pomiferis, Vmbelliferis, plurimis Liliacearum \& Cucurbitacearum, \&c. Quum interim Tubae, quae haec coronant, terminantque, quocunque demum loco ovarium fit um fit, femper intra forem comprehendantur. Manifefto equidem indicio, florem in confervationem organorum fexus utriufque natum modô effe, nequâquam verô in praeparationem fuccorum, qui nutrimentum primum praebent Embryoni fructus : nec enim aliud hic pabulum capit nifi â pedunculo fuo vel fuftentaculo, quo fimul alitur fulciturque totum integri floris corpus.

Ad ubas ut redeam, quas ante \& poft Malpighium, nemo in animum induxit bene diftinguere à ventre ovarii, quaeque quotidie nobis vix defignantur, nifi vagis fub no- 


\section{DISCOURS SUR LA}

vagues, comme de houpes dans le Safran; " d'aigrettes dains l'ozeille ; ${ }^{b}$ de feuilles dans la Flambe; ${ }^{c}$ de clous dans. la Fleur de Paffion; ${ }^{\mathrm{d}}$ de chapiteaux dans le Pavot; ' de filets dans le Mais $\mathfrak{G} c$. Eु aux quelles on ne donnoit pour toute occupation que le foin de décharger les jeunes fruits \&ु les embrions de graines, de leurs ordures ou excrements, quoiquion ne laifjat pas diailleurs, de les faire aller de pair avec le pittile ce fameux Cheval de bataille pour lequel on leur faifoit l'bonneur de les prendre en plufieurs occafions. Ces trompes, dis-je, que je compare a celles de Fallope, en ce qu'elles tranfmettent aux petits cufs, non pas les grains de pouffiere même qu'éjaculent fur clles, ou dans leurs pavillons, les tefticules ou fommets, comme le veut un Sectateur des vifions de Leeurvenboek E' d'Hartfoeker, mais seulement la vapeur, ou l'efprit volatile qui fe dégageant des grains de pouflere, va feconder les oufs. Car, je croi, Meffeurs, quion doit étre perfuadé que dans l'animal, ce n'eft ni la matiere du mafle, ni ces pretendus vermiffeaux ou animaux $f e-$ minaires, qui operent dans la femelle l'auvre de la fécondation, puisque le méme Malpigbi, au rapport d'un Anatomifte moderne, ${ }^{\mathrm{f}}$ a reconni que le Foetus fe trouve dans les aufs des. Grenoüilles छE dans ceux des Poules avant la copulation, comme il eft tres-certain que le germe fe rencontre dans les femences des Plantes quì n'ont point été fecondées, Ë avec le parenchyme défquelles ce germe ne fait qu'un contimu. Donc, cene peut être.que cet esprit volatil auquel la matiere grofiere fort fimplement de vebicule. Or la nature agiffant touijours par des Loix uniformes, on doit conclure que ce qui fe paffe en cette occafion dans les Animaux, fe doit pafer de méme dans les Vegetaux.

Suivant ce principe, il êtoit fort inutile que ce zelé Leeuwenboeckifte fe fatiguat tant les yeux a chercher dans les trompes des plantes des.conduits fenfibles pour sbarier dans chaque cuf un germe imaginaire; Ë qu'il aferînât con-

a Crocus. b Acctofa. c Iris. d Granadilla, e Papaver. f M. Dionis Edit. 4715. p. 322 . 


\section{STRUCTURE DES FLEURS, \&c。}

minibus, ut fcilicet in Croco vocantur Capillamenta capitat a Ef criftata; in aceto $\int \hat{a}$ pappus; petala in Iride; Clavae in Granadillâ; Capitellum in papavere; in Mays capillamentum. \&c. quibus fanê cunctis id tantum negotii datur, ut liberent fructus Juniores, Embryonefque feminum, â fordibus fuis excrementifque, licet aliâs habeantur pari ambulantia paffu cumpiftilln. Cum piftillo, inquam, decantatiflimo. amatifimoque objecto! in quo tam feriô triumphant. Pro quo faepius ut fumantur placuit lis, qui tam fplendido ea honore dignati funt. Tubae igitur hae, quas Fallopianis comparo quod ad ova deferant non exigua ipfa illa pulveris foecundi grana, quae tefticuli, aut apices fuper illas ejaculantur, aut in ipfarum excutiunt infundibulum, ut Sectator Leeuwenhoekianorum atque Hartfoekerianorum phantafmatum voluit, fed halitum modô, aut fpiritum volatilem, qui pulvere hoc fe expedit, ovaque ipfa foecundat. Credo enim, Auditores, perfuafum certumque habendum; non materiem mafculinam, nec vermiculos fuppofititios, vel animalcula feminalia, effe, quae impraegnationem in foemellâ abfolvant: quia idem Malpighius, narrante Anatomico(Dionis. Edit. I715. pag. 392.) recente, agnovit foetum reperiri in ovis ranarum, \& gallinarum, ante copulam: ut \& certiflimum eft, germen adeffe in feminibus plantarum, quae non fuerunt impraegnata, quorumque parenchyma facit cum germine ipfo continuum corpus. Non poterit igitur effe aliud quid, praeter volatilem hunc fpiritum, cui craffior materies vehiculi modô vicem praeftat fimplicis. Naturâ verô femper eafdem fectante leges, concludere oportet, id quod hâc occafione in animalibus contingit, idem $\&$ vegetantibus accidere.

Juxta haec principia, inutilis admodum eft labor, quo Strenuus Ille Leeuwenhoekianae fectae propugnator femer fatigat, oculofque fuos, ut quaerat in Tubis plantarum vifibiles ductus, quibus vehatur in fingula quaeque ova unum germen fictum; repugnatque veritati affertum, quo pro- 
contre la verité, que pour le peu que l'on fe veuille bien donner la peine d'ouvrir les piftiles (terme favori fous lequel it confond les trompes Ef les Ovaires) on reconnoitra tresdiftinctement qu'ils font toûjours ouverts a leur extremité, $\&$ percéz plus ou moins fenfiblement jufqu'a leur bafes.

On l'en aurvit peû croire fur fa parole, fi la plus part des preuves quil en donne avec un peu trop d'affeutrance ne le demantoient pas. 2u'on examine un peu les trompes dit Potiron a qui par leur énorme grofleur devroient le mieux quadrer a fon idée, E l'on verra $j$ elles font veritablement telles quil depeint, \&5 fi an contraire, on ne les trouve pas exactement bouchées a leur extremité \&ु remplies dans leur. longueur, de méme que la panfe de lovaire, d'une fubfance pulpenfe \&ु fucculente, qui ne scauroit, fans de tresgrandes difficultez, permettre au moindre grain de pouffere, de Je gliffer dans l'Ovaire.

A l'egard de la Pomme de Calvil b , comme fes trompes font fort pointuës \&ु aufit deliées a proportion que celles du Potiron font épaiffes, il eft hors de doute que leurs ouvertures Eु leurs canaux ne font pas plusréels; Et fi l'on remarque des fentes, des cavitez, ou des foffes au bout de certaines trompes, elles n'y font pratiquees que pour en etendre la furface छु recevoir une plus grande quantité de pouffere; a quoi fervent pareillement les têtes fongueufes Eg gremues, les cornes, les filets, les boupes, les aigrettes, les panaches, les poils, le velouté Ecc. que lon rencontre fur diverfes iroupes.

Mais quand on lui pafleroit l'exiffence de ces pretendus conduits, Es la pofibilité de lintromifion des grains de pouffiere jufque dans la capacité des Ovaires, en concevroit-on mieux par ou ces mémes grains predefinez entre tant d'autres, pourroient penetrer dans les cuffs diun Ovaire qui n'auroit qu'une cavité, comme par exemple, celui de la Primevere, on les cuifs font amoncelez fur un placenta, Jitué dans l'Ovaire a peu prés comme un fruit

a Melopepo. b Erythroinelon magnum Parifiacim J. B. L. I4. 
profitetur, I parvo tantum labore aperiat quis piftillum, (vocabulum Auctori huic acceptiffimum, quo confundit tubas \& ovaria,) diffinctiffimè detecturum effe, femper illud ad extremitates fuas apertum, pertufumque, magis, minufue, ufque in balin ipfam.

Verbis Viri credula potuiffet adhiberi fides, nifi maxima pars argumentorum, quae confidenter nimis profert, falfitatis ipfam fententiam clarê argueret. Examinet modô propius Melopeponis Tubas, quae ob enormem magnitudinem optimê refpondent ideae illius, tumque apparebit, verêne ita fint quales depictas dedit, conftabitque, an non e contrario femper deprehendantur quam accuratiffimê in fuis extremitatibus obthuratae, infarctaeque totâ fuâ longitudine fimili pulpofâ fubftantiâ ut ipfe Ovarii venter? Sanê eam cernet talem, quae non fine rnaximâ quidem difficultate minimum tranfmittat granulum pulveris illius, ut in ovarium fe infinuet.

Refpectu Erytbromelonis magni Parifaci J. B. I. I4., qui tubas habet valde acutas, tenuefque, fi fpectes Melopeponem, qui craffiores habet, certum eft, harum aperturas, canalefque, aequê parum vera haberi.. Si autem fiffurae videntur, cavitates, vel foffulae, circa apices quarundam tubarum, non aliâ profectô hae gratiầ-ibi natae, quam ut expanfa in amplam fuperficie abundantiorem excipiant copiam foecundi pulveris ; cui eidem propofito pariter ferviunt fungofa capitula, \& crenis incifa, cornicula, filamenta, pappi, capitula tomentofa, plumulae, cirrhi, villi, \&zc. quae faepe diverfis in tubis inveniuntur.

Quid fi concedatur Ipfi fictorum horumce ductuum prafentia, fimulque detur, poffibilem granorum pulveris defcripti admifionem ufque in capacitatem ovariorum, an inde pulchrius intelligetur quonam pacto eadem grana inter tot alia deftinata poffint fe penetrare in ovula Ovarii unâ tantum cavitate donati, ut Ex. gr. in primula veris, ubi ovula omnia eidem placentae affixa fitae in ovario fer- 
d'Alkekengi l'êt dans fa veffie, ou une bobeche dans une lanterne. Car alors, il faudroit qu'il arrivât nece Sairement de deux chofe liune, ou que ces grains caffafent la coque des cenfs pour se pouvoir nicher deflous, on que prenant une route plus longue, ils fe coulaffent entre ces cenfs, qu'ils percaffent le placenta pour l'enfiler, $\mathcal{E}$ de la paffer dans les oufs. C'es routes paroifent elles naturelles E̋ bien pratiquables?

Peut étre me fera t-on la même objection a l'egard de ce que j'ai avancé touchant cette vapeur, cet efprit volatile, ou fi jofe me fervir du terme de la Genefe, de ce foufle, lequel fortant des poufleres, va vivifier, aniimer, Es a l'aide du fuc nourrifier, developer ces racourcis des plantes, on les germes de leurs petits aufs. Mais la reponfe eft toute prefte, la voici. Les trompes n'êtant qu'un prolongement de la panfe de l'Ovaire qui eft une envelope compofée de méme que les tiges, de deux fortes de tuyaux, fgcavoir de ceux qui cbarient les fucs alimenteus, Ef de ceux qu'on nomme trachées, lefquelles, felon Malpighi, font dans les plantes, les fonctions de poulmons, il eft aifé a ce foufle de s'infmuer par ces derniers vaiffeaux. qui se terminent a la furface des pavillons, laquelle furface eft denué de la pean qui recouvre le corps des trompes; il eft, disje, aifé a fe foufle de paffer des trachées, d'abord dans la bafe du placenta qui perce le fond de lOvaire, enfuite le long de fon corps spongieux, E⿱ delà fe diftribuer parles cordons umbilicaux, jusque dans chaque petit germe qui prefente fa radicule an trou de la coque de l'cuf avec lequel s'abouche le cordon umbilical, pour recevoir de ce cordon EF le foufle. E la nourriture.

Qu'on épargne de tortures a fon epprit, E de reproches à la nature, en s'en tenant a ce dernier raifonnemént! Qui eft-ce qui pouvoit simaginer quiun prisme a quatre faces devint la Penfée ${ }^{2}$; un rouleau étranglé, la Bourrache; un rein, la Fonquille; qu'une croix $\int e$ peut metamorpho-

2 Viola fpecies. 


\section{STRUCTURE DES FLEURS, \&c}

me ut Alkekengi fruetus intra fuam veficam, aut ut tubus candelam excipiens in laternâ. Oporteret enim eo cafu alterutrum accideret, aut nimirum, ut grana haec teftulam ovulorum frangerent ut fubtus nidularentur, aut, ut longiore planê viâ irreperent inter ovula, perforarent placentam, ut fe introducerent eô, indeque tranfirent in ova. Videntur ne hae vobis viae naturae convenire, videnturne poffibiles efle.

Sed, forte, eadem mibi objectio movebitur Statuenti Similia fere circa halitum illum, Spiritumve volatilem, aut, fi ita loqui fas fit phrafi Genefios, iftum incubantem flatum, qui pulvere illo exhalans, vivificat, animat, atque ope fucci nutrititii explicat iftas in compendia convolutas plantulas, aut prima germina exiguorum ovulorum. In promptu eft refponfio ; en illam. Quum ipfae Tubae productiones fint ventris ovarii, qui amiçus eft, ut ipfi trunci, compofitus duplici tubulorum fpecie, iis fcilicet, qui fuccum vehunt alimentitium, iifque, quae appellantur Trachaee, quae, Malpighianấ quidem Sententiâ, funguntur officio pulmonum. facile itaque vapori illi halituofo ultimis his fe vafis infinuare, quae terminantur in explicatâ fuperficie infundibuliformi ovarii, illa verô fuperficies caret nuda illâ pelliculà, quae corpora tubarum ambit. Eft itaque expeditum fatis huic halitui intrare, tranfire, has tracheas ilicô in bafi placentae, quae perforat fundum ovarii, indeque per productum ejus fpongiofum corpus fe penetrare, atque exin diftribuere $\mathrm{fe}$ per Chordas umbilicales ufque in unumquodque parvum germen, quod radiculam fuam offert teftulae ovi, cui per anaftomofin unitur funiculus ille umbilicalis, ut per eum accipiat \& pabuli fuccum \& halitum illum praegnantem:

Definant itaque crucem figere animo fuo! abfiftant exprobrare bonae Naturae errores! inhaereant ultimae huic Sententiae! Quis, amabo Vos, Quis, inquam, imaginandoaffequeretur unquam, prifma tetraedrum mutari in violam tricolorem? convolutam arctê philyram in Borraginem? renem in Narciffum folio junci; crucem in Acer; binos glo- 
fer en Erable ; deux boules de criftal étroitement collées T'une \& l'autre, en Grande confoude Ëc. ? Ce font cependant là les figures qu'affectent dans ces diverfes Plantes leurs Embrions aux pieds poudreux. Et qui eft-ce qui ne décbaineroit pas contre des méres, quii n'engendreroient tant de $\sqrt{l}$ beaux Enfans que pour le plaifir de les perdre par aprés fans refource., Es confier au caprice du bazard, le foin d'en fauver feulement quelques uns. Car enfin, l'on voit des fleurs qui aiant jufqu'a vingt cing on trente étamines (comme la pluspart de celles des fruits à noyau) ne contiennent cependant qu'un feul auf. Que de germes detruits! $\sigma^{\prime} e f t$ ce que je laiffe a Jupputer parle prodigieux nombre que chaque fommet en expulse, où par ce qui en refte dans fon fein d'ou il u'eft pas toujours neceffaire que ces grainis de pouffiere denichent, fi ce ne fontceux des fleurs Iteriles; car ces derniers devant étre charicz par l'air fur les fleurs fertiles, s'envolent tous, foit par leur fechereffe ES legereté naturelle; foit par la rude Eु brufque fecouffe quills recoivent de la forte contraction de leur capfule, Au lieu que ceux des flours ou fe rencontrent les deux fexes, pour fe trouver tout portes fur l'objet defiré, font en comparaifon des autres, de vrais ciùs de jatte, qui aprés s'être énervez par de longs \&5 doux écoulements de leur foufle prolifique, reftent en partic dans leurs capfules beante, ou fe qui s'en accroche aux trompes, $y$ demeure $\&$ fe deffeiche avec elles.

Mais avant que de fortir de la pouffiere, il faut que je rapporte une objervation qui feule fuffit, ce me femble, pour culbuter le fyfteme ingenieux de celui qui a tant pris de plaifir à la faire voler fans qu'il m'en foit entré le moindre grain dans les yeux. 2u'on examine bien le Papaver Orientale hirfutiflimum, flore magno. Cor. F. R. Herb. 17. Sa aprés que la fleur de cette plante eft épanoüie l'on en ouvre lovaire tranfuerfalement, ou de base en baut, on tronvera que les feïillets de fon placenta Eु les petits aufs 


\section{SRUCTURE DES FLEURS, \&C.}

bulns cryftallinos arctiffmê ad fe invicem agglutinatos, in Confolidam majorem? \&c. hae tamen figurae funt, quas gerunt Embryones in diverfis plantis ad pedes pulverulentos. Quis tandem ille, qui non inveheretur quam acerbiffimê in matres, pulchros adeô liberos quae parerent tantum ut poftea cum voluptate eofdem necarent, abfque ullà. fpe novae nativitatis, atque committerent foli fortunae forti curam fervandi quam pauciffimos? Enimverô, flores videmus, qui habentes ad viginti, imô triginta quandoque, ftamina, ut pleraque earum pars, quae fructum gerunt offeo foetum feminis putamine, tamen unum modô ovum continent. Quantum hîc germinum deftruitur! Supputetur id folum modô ex prodigiofo numero, quem apiculorum quilibet expellit; vel ex eo, qui reftat in finu tefticulorum, unde ut nidum fuum deferant omnia ipfa pulverulenta grana, neceffarium femper non habetur, nifi in floribus forte Sterilibus. Poftrema quippe haec, per aerem quum vehenda fint ad flores fertiles, cuncta avolant, five ariditate id nativâque contigerit levitatê, five rudi fiat $\&$ impetuofo concuffu accepto â violentâ capfularum contraçtione. Verum contrarium obtinet in germinibus florum, qui utrumque fexum habent; ut enim tota feruntur in amatum objectum, ratione habitâ priorum, verê funt mutilata corpora, quae poftquam enervarunt femet diuturno, dulcique halitus foboliferi effluvio, partim fuis in loculis morantur hiulcis, aut partim affixa tubis haerent, in iis manent, cumque iifdem ibidem exarefcunt.

Antequam verô ex hoc me pulvere expediam, oportet adferam obfervationem unicam modô parem deftruendo, ut opinor, fubvertendoque ingeniofo Syftemati Auctoris, Cui tam volupe fuit excitare tantum volitantis pulveris, cujus tamen mihi ne minimum quidem in oculos infilit granulum. Examinetur ritêPapaver; orientale; birfitiffimum; flore Magno. Tourn.Cor.R. Herb. 7 . Certê, fi, aperto prius expanfoque flore hujus plantae, ovarium ejufdem perpendiculari inciditur fectione, five â bafi in verticem,reperientur lamellae placentae, 


\section{${ }_{24}$ DISCOURS S UR LA}

oufs qui les couvrent, font blancs, quoique les trompes foient cependant toutes imbibées de la teinture que leur fuc a tiré des grains de pouffere qui s'y font épanchez. D'ou l'on doit inferer qu'il n'en entre aucun grain, ni dans ces feuillets, ui dans les oufs: car s'il êtoit vrai qu'il y en entrât, on ne pourroit les y perdre de veî̈ë, tant a caufe de leur couleur d'Indigo; que par la quantitê qu'il en faudroit pour la multiude d'cufs dont ces feuillets font chargez de part छु d'autre.

Au fur plus, le public doit être obligé a cet babile Phyficien, Io. De ce qu'ayant reconnu par des obfervations tresexactement faites dans le Cabinet, que la feule fupprefsion. des pouflieres êtoit capable de faire avorter les fruits, couler la Vigne, nieller, échauder, brufler Eु ergoter les Bleds, il l'a $f$ beureufement tiré de cette erreur ruftique, qui hii faifoit attribuer tant de facheux evenements, aux pluizes froides, a la fraicheur de la terre, a la gelée, aux brouilllards épais EF puants, EF enfin a des coups de Soleil, tout meurtiers, difoit-on, qui aprés avoir engourdi la feve, pincé, étranglé, cauterifé, छु déchiré Jes vaiffeaux, alteré \&ु detruit totalement la tifure $\mathfrak{E}$ la fubftance de ces delicats Embrions, les faifoient a la fin miferablement perir.

20. De ce que ne s'êtant point encore appercế que les cufs des Poulles qui vivent dans le celibat Eु la contimence, doivent (a l'inftar des fruits qui n'ont pas été engroffez de ce tout-puifant grain de pouficre,) étre moins gros, moins pleins, \&5 moins bons a manger que les autres; il prendra d'oresnavant un grand foin de donner de bons mafles à ces chaftes femelles, afin d'avoir d'excel lents oufs.

Fe reviens aux differents fexes des Plantes. Comme tout le Monde Sçait quils ne fe tronvent pas toîjours rafemblez dans une méme fleur, E qu'au contraire, l'un eft fouvent feparé de l'auire, tantôt fur le méme individu, tantót fur des pieds differents, j’ai creib a cette occafion 
parvaque is adhaerentia ova, candida, licet interim tebae fint tinctæ penitus pigmento, quod fuccus carum haufit ex granis pulveris diffufíf fuprâ tubas. Unde concludere oportet, ne unicum fanê granum ingredi nec lamellulas placentae, neque vel ova ipfa: Si enim intralfe hæc effet verum, poffent profectò vifu fatis ibidem deprehendi, tam ob colorem Indicum, quo fplendent, quam propter copiam eorum numerofam, quae requireretur impraegnandis tam multis ovis, quibus oneratæ funt ab utrâque parte lamellae ovarii.

Denique de Publico optimê meruit Egregius hîc Phyficus; Primô quidem, quod expertus, per obfervationes curatiffimê in mufaeo captas, folam Suppreffionem pulverum horum aptam effe natam ut abortire cogat fructus, Stillare vites, uftilagıne perire, percoqui, exuri, \& marafmo arefcere, fruges Cereales; feliciter liberavit homines ab eo errore ruftico, quo tribuebantur infaufti hi eventus frigidis imbribus, frigori telluris, gelu, nebulis fpiffis putridifque, denique ardori Solis exitiali, qui, ut ajebant, torpido reddito prius humore nutrititio, comprimit, Suffosat, comburit, lacerat, vafcula, immutat, deftruitque, penitus texturam, molemque tenellorum Fmbryonum, miferâque tandem morte eos enecat. Sed \& eo quoque nomine obftrictum fibi hominum genus reddidit, quod ignarum prius, ova gallinarum in coelibatu viventium \& abftinentiâ debere effé minus magna, minus plena, minufque apta menfis quam alia, (inftar fructuum non impraegnatorum omnipotente grano pulveris) in pofterum curam geret, ut mares falaces copulent caftis hifce foemellis, ficque ova habeant optima.

Redeo ad fexus plantarum diverfos. Notum quum fit omnibus, haud femper unitos reperiri in uno eodemque flore, contrâ verô hunc faepe remotum ab altero effe, quandoque fuper eâdèm plantâ, quandoque diverfis planê in Stirpibus, crediderim hâc occafione 
devoir établir de trois fortes de fleurs, fgavoir de Mafles, de Femelles $\mathfrak{E}$ d'Androgines ou Hermaphrodites; noms qu'un doux E़ officieux Ecbo a a bien ioulu repeter (au moins les deux premiers) dans une Royale afembleé, pour les transmettre par avance a la pofterité ainsy que quelques antres particularitez quil u'd pas fi fidellement rapportées; quoy qu'on ne lui en eut pas fait plus do myftere, croyant boninement quil niappartenoit quaul Corbeau de la fable, de fe parer des plumes du Geay. Mais a Dieu ne plaife que je veüille revendiguer ces particularitez fl defigurées E. Lui cnvier la moindre de tontes les jolies chofes. quil a butinées par ci par la dans les autbeurs pour en grofir ces obfervations; on lui abandonne de bon cour les unes ES les autres pour s'en tenir a la pure nature, feul livre quil faut feüilleter pour n'être pas trompé. ES pour nen impofer à perfonne.

Les Fleurs Mafles que les Botaniftes modernes nomment. Steriles ou Fauffes-fleurs, font celles qui ne conticnnent que les organes mafoulines dont jai parlé.

Les. Femelles, que ces mémas Botaniftes appellent Fleurs nouiées, oü Fleurs à fruit, ne renferment que l'ovaire ou feulement les trompes qui, comme jai desja dit, font les parties Juperieures de cet organe feminin.

Et les Fleurs Androgynes oir Hermaphrodites auxquelles ils nont point donné de nom, font enfin celles ou lés deux jexes fe trouvenis conjointemeni.

Je palfe anx calices qui n'eftant point des parties effenticlles aux fleurs, ne fe rencontrent pas anfi daus tontes. Ain $\mathrm{L}$ je nomme les unes Fleurs à calice, où Fleurs complettes, ¿छ les autres, Fleurs fans calice ois Fleurs incomplettes.

On entendaffez que le calice eft a la fleur, ce que la fleur eft aux organes de la géneration; c'eft a dire quil hii fert principalement d'envelope, furtont lors qu'il eft de plufieurs pieces: car entre less calices dune Senle piece, il: s'en voit de fi courts, quils ne peuvent fervir que de doüille Es d'emboiture a la partic inferieure de la fleur, poun l'asfujetir EG l'affermir en piace.

Cela a l'Autheur des obfervat. furlin.ftructure \& l'ufage des principales parties des fleurs. 
tres me debere Stabilire florum fpecies, Mares fcilicet, Foemellas, \&ु Androgynas feu Hermaphroditos, nomina, quae fuavis officiofufque defcriptor lubens repetivit, priora certê bina, in confeffu Academiae Regiae, ut eadem praematurè tranfmitteret pofteritati, ut \& alia quaedam fatis fingularia, quae tantâ quidem fide non recitavit, licet fanê neque haec ipfum celaffem ut myfteria quaedam. Credideram etenim bonâ fide non decere nifi Corvum fabulae ut fe ornaret plumulis Graculi. Sed prohibeat Deus, ne mihi vindicare velim fingularia quaeque adeô deformata, neve invideam ipfi quidpiam elegantiarum, quas hinc inde rapuit, compilavitque, ex Auctoribus ad augendas obfervationes! Liberali unum alterumque animo fuo haec $\mathrm{Au}-$ ctori cedimus ut uni inhaereamus Naturae, uni fcilicet libro, quem verfare oportet unum quemque, qui nec falli cupit, neque ftudet decipere.

Flores mafculi, quos Botanici Recentiores Steriles Sposriofve flores appellant, funt illi, qui fola organa mafculina continent, de quibus jam dixi.

Foemellae flores, quosBotanici Flores proliferos vocant vel Fructiferos, iola comprehendunt ovaria, aut folas Tubas, qux funt; ut modô explicui, Superiores organi foeminini partes.

Aindrogyna autem, vel Hermaploroditi flores, quibus fingulare haud dederunt nomen, funt denique illi, ubi bini fexus uniti in uno Flore apparent:

Ad calices tranfeo, qui quum non fint partes ad floris naturam abfolutè requifitae, idcô neque in omnibus deprehenduntur floribus. Appello propterea hofce flores calice infructos, aut flores completos, , alios verô flores calice carentes, aut incompletos flores:

Satis intelligitur, calicem id praeftare flori, quod flos genitalibus; fcilicet fungit ur integumenti officio imprimis,praecipuê quoties in multas partes divifus habetur. Namque inter calices unâ modô conftructos continuatâ fabricâ, , apparent adeô curti quidam, ut infervire néqueant nifi loco tantum Suftentaculi; , aut pyxidatae bafios, floris parti inferiori, ad eum fuftinendum, fuâque firmandum in fede.

D. 2

Quo 
Gela pofé, il s'agit prefentement, Mefleurs, de Vous donner des expedients pour connoître an premier coup decil fi. le calice eft d'une feule piece ou de plufieurs; car faute de Metbode, les plus grands maîtres s'y font fouvent trompez ainfi qui a l'egard des fleurs.

On connoît que le calice eft d'une feule piece (bien qu'il ne le paroife pas, êtant decoupé jufqu'a fa bafe) Si en tirant un de fes lobes, il fait refiftance, EG fe déclsire plütôt que de fe détacher nettement du pedicule. On le connoitra encore mieux, fi lon s'apperçoit que ce calice fubfifte après que la fleur eft tombée; car les calices de plufieurs pieces n'êtant que contigus, collez, ou articulez, pour ainfi dire, avec le pedicule, tombent ordinairement, ou avant la fleur, comme au Pavot, a la Chelidoine F̧c. où en mêtme temps, on immediatement aprìs, comme à la Renoncule E aux plantes cruciferes. Au lieu que les calices diune feule piece, s'ufent plutiôt que de fe détacber de leur fupport ou ils font continus, n'en étant proprement que des

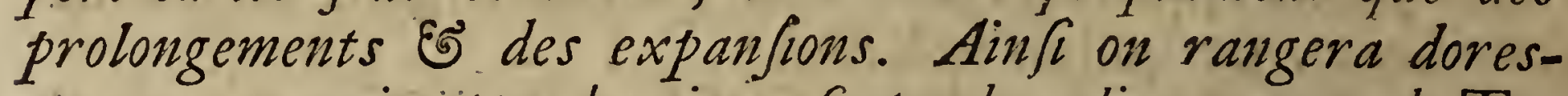
navant parmi cette derniere forte de calice, ceux de Telephium, d'Helianthemum, $d$ 'Androfaemum, d'Hypericum, d'Afcyrum de Ruta de Paeonia de Linum, d'Alfine Ëc. quion veut nous faire paffer pour calices de plufieurs pieces.

Si le calice couronne l'Ovaire oul Embrion du fruit, ce qui eft la méme chofe, il eft bors de doute, qu'il eft d'une feule piece, EG quili ne fait quiun corps avec cet Embrion. Donc les calices de Circæa \&ै de Chamænerion qu'on dit être de phufleurs pieces, ne font que d'une feule.

On doit encore compter que le calice eft d'une feule piece, lorsgue la fleur l'eft auffi: Et on ne voit guere de calices a phufieurs pieces qu'aux plantes que j'ai desja nommées qui font les Cruciferes, anx vrayes efpeces de Renoncules, an Pavot, an Glaucium, an Corchorus, an Chelidonium, a $l$ 'Hypecoon, a $u$ Leontopetalon, a l'Epimedium, ala Chriftophoriana \&' a quelques unes dont l'Ovaire s'ouvre en valife 


\section{STRUCTURE DES ELEURS, \&c.}

Quo pofito, id agitur, Auditores, ut Vobis ea proponantur quae expediant rationem, quâ primo obtutu cognofcatis, Sitne calix unâ conftructus, pluribufve partibus: defectu namque methódi Principes in Arte Magiftri faepe numerô decepti funt, aequê ac floribus ipfis.

Scitur unâ parte conftare calix, licet talis non appareat, utpote divifus ufque ad bafin, fi trahenti unum loborum refiftit, faciliusque dilaceratur, quam ut patiatur integrê fe divelli à fuo pedunculo. Item clarius adhuc id cognofcitur, fi advertitur calicem perfiftere flore jam delapfo; calices enim polyphylli, quum modo contigui fint, conglutinati, aut articulati, ut ita loquar, fuis pedunculis, frequenter facilê cadunt, aut ante florem, ut in papavere, C'belidonio, \&c, aut eodem, aut ftatim fubfequente, tempore, ut in Ranunculo plantifque Cruciferis, quum contra calices monophylli plerumque confumantur magis, quam ut femet $\hat{a}$ fuftentaculo fuo feparent, quocum continuati funt, utpote quum propriê fint tantum pedunculi fui productiones, expanfionefque. Ordinabimus igitur deinceps in ferie pofterioris Speciei calicum, perianthia Telephii, Heliantbemi, AndroSaemi, Hyperici, Afcyri, Rutae, Paeoniae, Lini, Alsnes, $\mathscr{G}_{c}$, quos nobis perfuafum volunt calices effe polyphyllos.

Si calix ovarium coronat aut Embryonem fruetus, quod unum eft idemque, certum eft, efle monophyllum, unumque cum Embryone corpus conflituere. Calices ergô Circaeae हु Chamaenerii, quas polyphyllos vocant, monophylli tantum habendi erunt.

Putare quoque decet, calicem monophyllum effe, quoties monopetalus fos eft: neque fere polyphylli inveniuntur calices, nifi plantis jam Statim enumeratis, Cruciferis, Ranunculis Veris, Papaveri, Glancio, Corchoro, Chelidonio, Hypecoo, Leontopetalo, Epimedio, Chriftopboriane, \& quibufdam, quarum ovarium fe aperic 
life c'eft a dire d'un bout a bautre, Gु d'un feul côtế, foit que cet ovaire foit fimple ou compofé; Et alors la couleur de leurs calices, qui jusqu'a prefent, ont été pris pour leurs fleurs, eft fembiable a celle des petales de ces mémes feurs. C'eft ce qu'on remarque dans l'Aconitum, le Delphinium, la Nigella, l'Aquilegia E̋c.

Si l'on demande pourquioi toutes les fleurs n'ont point de calice, on repondra que celles qui font d'une confiftence épaiffe, ou cbarnuë, ainfl que les teguments de leurs ovaires, comme en la phípart des Plantes Liliacées, a la Pulfatilla Ëc. n'en avoient que faire, êtant de leur nature a l'épreuve de tout évenement. Et que le Createur dont l'infinie fageffe éclate Đु fe fait admirer jufque dans fes plus petits ouvrages, nien a donne de bien marquez qu' a trois fortes de fleurs. $x^{\circ}$. a cellez qui pour être trop minces \&ु trop delicates, comme au Pavot, au Cifte Eัc. n'auroient peî fans cette eppece de furtout, refifter aux moindres injures du temps, $2^{\circ}$. a celles qui pour avoir des petales trop courts EE trop étoits, auroient exposé a nud des organes analogues à ceux que la pudeur veut abfolument que i'on cache, lefquels fe feroient fletris \&ु ufez avant que de pouvoir fervir. Telles font les fleurs de l'Elleborus niger, de l'Aconitum de la Nigella E̋ c. $3^{\circ}$. Enfin il en a pourvent tout de celles dont la cheîte auroit indubitablement été fuivie, de la perte des Ovaires, qui pour fe trouver compo$f_{\epsilon} z \xi \mathcal{E}$ tres foiblement attacbez autour d'une espece d'Axe, comme dans les Plantes Aviferes ou Labiées, dans les Borraginées, dans une partie des Malvacées E̋c. Se Seroient dètachez au moindre ébranlement, s'ils n'eufent été appuizez ou addoffez d'un calice; ou qui pour étre d'une étoffe fort legere, comme au Geranium a la Maure छ̋c, auroient bientôt peri par trop de chand ou trop de froid, Jans l'abry de ce rempart, qui le plus fouvent eft double dans les plantes Malvées. Après vous avoir donné des moyens ponr bien demefler les calices d'une feule piece d'avec cenx de plufieurs pieces, je vais vous dire prefentement comment on peut difcerner les fleurs monopetales des polypetales. 
inftar Ciftellae bivalvis, ab uno fcilicet in alterum extremo, atque $a b$ uno folum latere, five fimplex id ovarum five fuerit compofitum; tumque color calicum, qui hactenus florum loco habiti, colori petalorum eft fimilis eorundem florum. Id in Aconito, Delpbinio, Nigellâ, Aquilegiâ Ẻcc. obfervatur.

Roganti, cur omni flori calix haud adfit? refpordetur, eos, quorum craffa, carnea, materies, lit \& tegumenta ovariorum eorundem, ut in plurimis plantis Liliaceis, in Pulfatillâ, \&c. obtinet, non egere calice, utpote fuâ jam naturâ fatis fortes eventus quofque fuftinere, Creatoremque, Cujus infinita Sapientia fulget, fuique admirationem excitat ufque in minimis opufculis fuis, haud impertiiffe perianthia nifi tribus folummodo florum Speciebus.. r. iis, qui ob tenuitatem nimiam \& teneritudinem, haud valuiffent ferre abfque calicis adminiculo vel leviffimas aëris injurias ut in $P$ apavere $\mathfrak{S}$ Cifto $\mathcal{E}^{2}$. 2. iis, quibus ob nimiam petalorum parvitatem, brevitatem, gracilitatemque, organa fimilia iis, qux pudor naturalis abfolutè tegenda praecepit, nuda expolita fuiffent, ficque confumta fuiffent \& emarcida anteaquam fuo poterant fungi munere. Tales funt flores Hellebori Nigri, Aconiti, Nigellae \&rc. 3. denique donavit calice omnes, quorum caducus lapfus neceffariô traxiffet fecum perditionem ovarii, quod quum nimis multas partes componentes, debiliterque valde nexas ad ambitum axis cujufdam, haberet, ut in plantis Aviforis, aut Labiat is, in Borragine, in aliquâ Malvacearum, minimo certê impetu, concuffuve fuâ excidiffer fede, niff fuffultum fuiffet aut inveftitum calice: aut quod, ob materiem nimis levem, ut Geranio, Malva, \&c. citô periiffet nimio calore, aut frigore, fine defenfione bujus propugnaculi, quod quam frequentiffimê gemimatum habetur in Malvaceo genere.

Adjumentis igitur Vobis praeftitis, quorumbeneficio calices ritè extricare poffitis \& fecernere monophyllos â polyphyllis, aggredior jam Vobis dicere, quonam modo diftiuguere fas fit polypetalos a monopetalisfloribus. Quo- 
Si les fleurs font incomplettes ou fans calice qu'elles fubjiAlent, s'accroiffent, GG Jervent d'envelope au fruits apres la cheîte des étamines, il eft confant quielles ne peuvent eftre que d'une fenle piece, Es par confequent que de fimple prolongements de leurs pedicules, encore quion nous les donne la plipart pour des corps compolez de plulieurs pieces. Telles font les fleurs de Beta, d'Acetofa, d'Atriplex, de Spinacia, de Mercurialis, de Kali, de Veratrum, d'Amaranthus, de Potamogeton E̋c.

Le contraire arrive aux fleurs polypetales incomplettes, lefquelles fe fletriffent E़ tombent ou avant, ou en même temps que les étamines, laiffant l'ovaire a nud: comme celles de Tulipa, de Lilium EGc.

Quand la fleur eft complette हु que fon calice eft de plufieurs pieces, la fleur l'el indubitablement aufy. Mais fi le calice eftant d'une seule piece, la fleur paroiffoit l'être pareillement, alors pour prononcer jufte, il faut avoir recours a l'origine des étamines: car $\sqrt{l}$ elles partent des parois de la fleur, c'eft une marque afeuirée qu'elle eft monopetale, comme celle de la grande Gentiane: au lieu que $\int_{l}$ elles fortent immediatement de la baje de l'ovaire, c'eft figne que la fleur eft polypetale. Donc il faut rapporter la fleur de Ficoides parmi les polypetales quoiqu'on l'ait mije a au rang des monope'tales.

Dans les fleurs mafles, ain 1 que dans les Hermapbrodites, le nombre des tefticules ou étamines, n'eft pas d'un petit fecours pour débroüiller les monopetales des polypetales; les premiers n'ayant communement qu'autant de tefticules que de découpures: comme dans les fleurs des plantes Rubiacées, Borraginées Eुc. Quelquefois elles en ont moins, comme les fleurs de Veronica, de Liguftrum, de quelques efpeces de Jafmin Ec. Et je ne fyache guere que celles de Styrax, de Cotyledon major, d'Arbutus, de Vitis Idæa, d'Erica, d'Acacia, de Mimofa,

2 Mem. de l'Acad. R. des Sc. ann. 1705. P. 239 d'In- 
Quoties incompleti funt, five calice deftituti, fiores, fi perftant, crefcunt, fructibus integumenta dant, poft collapfa ftamina, femper funt monopetali, funt itaque tum fimpliciter producta pedunculorum fuorum, licet ut plurimum nobis exhibeantur ut corpora ex multis partibus compofita. Tales funt flores Betae, Acetofae, Atriplicis, Spinacbiae, Mercurialis, Kali, Veratri, Amaranthi, Potamogeitonis, \&c. Polypetalis autem Floribus contra evenit non completis, qui marcefcunt, caduntque ante, vel fimul, cum ftaminibus, ovariumque relinquunt nudum, ut in Tulip $\hat{a}, L_{i}-$ lio, \&c.

Quando flos completus, ejufque calix polyphyllus, femper, certôque \& flos polypetalus erit, fed monophyllo calice, fi flos quoque talis apparet, tum jufta ut feratur fententia oportet recurrere ad ftaminum originem : fi enim oriuntur ex parietibus floris, certa haec nota eft floris monopetali, ut in Gentiana majore. Quum contra fiat, ubi oriuntur directê ex bafi Ovarii, id enim polypetali floris fignum habetur evidens. Quapropter decet Ficöidis florem teferre inter polypetalas, quamvis monopetalis infcriplerint hactenus. Mem. de L'ac R. des fc. anno 1705. p. 239.

In mafculis pariter \& hermaphroditis floribus, tefticulorum numerus aut ftaminum non parvi adminiculi eft extricandis monopetalis ex polypetalorum ordine; quum mafculi flores frequentiffimê tot habeant tefticulos, quot incifurae fint: ut in plantis Rubiaceis, Borragineis, \&c. quandoque pauciores poffident, ut in floribus obtinet Veronicae, \& Ligufri, quarundam Fafmini Specierum, \&c. nefcioque praeterea fere nifi \& Styracis, Cotyledonismajoris, arbuti, Vitis Idaeae, Ericae, Acaciae, Mimojae, $\mathrm{E} ; \quad I n-$ 
d'Inga, Es de quelques autres plantes Legumineufes, qui aient plus d'étamines que découpures. Au lien que le plus grand nombre des fleurs polypetales, tant celles qui portent fur l'Ovaire, que celles qui le renferment, foit qu'elles foient complettes ou incompleties, ont plus de tefticules que dc petalss. La feur de Balfamina, par exemple, a cinq tefticules contre quatre petales; celle d'Hippocaftanum, fept contre cinq; celle de Cardamindum \& de l'Acer, buit contre cinq; celles des plantes cruciferes, fix contre quatre, quelque fois plus, (ce qui eft fort rare) mais jamais moins. Les fleurs d'Herba Paris, de Geum, de Saxifraga, de Sedum, d'Anacampferos, de Salicaria, d'Onagra, de Chamaenerion, de Geranium, de Ruta, de Fabago, de Tribulus, de Fraxinella, de Caryophyllus, de Lychnis, de Myofotis, de quelques Alfine, de toutes plantes Legumineuses papilionacées, de l'Oxycoccus, de l'Azedarach E' d'Oxys, ont toutes une fois plus de tefticules. que de petales. Celles d'Harmala en ont quinze contre cinq; Et $f$ du reftant prodigieux de ces fortes de fleurs, on en excepte feulement celles des Vmbelliferes E़ de quelque peu d'autres genres, dans lefquelles on rencontre les tefticules E fleurs de tous les autres genres en ant pour alnsy dire, des Legions.

$A$ l'egard des fieurs monopetales Hermaplirodites dépourvenies de calice, j'en ai remarqué de quatre fortes par rapport an nombre de leurs tefticules comparé a celui de leurs découpures. Dans la premiere forte on trouve moins de ceax $-c i$ Es plus de celles-la. Dans la feconde, le nombre des uns Eु des autres eft égal. Dans la troifiéme, on compte une fois plius de tefticules que de decoupures; Et dans la quatriéme forte, le nombre de ces organes mafculins eft encore plus grand que dans celles de la troifiéme.

De la premiere-forte, font les fleurs de Valeriana, 
Ingae, quarundamque aliarum leguminofarum, quae plura ftamina poffident, quam incifuras; quum ê contrario maximus numerus polypetalorum florum, five Ovario infiftant, five idem comprehendant, five completi fuerint, five imcompleti, plures tefticulos habeant quam petala. Flos Balfaminae ex. gr. quinque tefticulos, petala quatuor, habet; Hippocaftani feptem ftamina, quinque petala; Cardamindi \& Aceris tefticulos octo, quinque petala ; Cruciferarum fex tefticulos, petala quatuor, aliquando, fed rarô, plura, nunquam pauciora. Flores herbae Paris, Gei, Saxifragae, Sedi, Anacampferotidis, Salicariae, Onagrae, C'bamaenerii, Geranii, Rutae, Pyrolae, Fabaginis, Tribuli, Fraxinellae, Caryophylli, Lychnidis, Myofotidis, quarundam Alfinarum, omnium Plantarum Leguminofarum Papilionacearum, Oxycocii, Azedarach, Oxyos; duplum habent tefticulorum ratione petalorum. Harmala quindecim ftaminula, quinque petala, gerit. Et fi ex reliquis numerofiffimis hujus fpeciei Horibus, folas Umbelliferas, \& paucas alias aliarum fpecierum exceperis, in quibus reperiuntur tefticuli petalis aequales numero, flores omnium aliorum generum habent, ut ita loquar, legiones.

Quoad flores monopetalos, Hermaphroditos calice deftitutos, obfervavi eos ad quatuor poffe referri fpecies ratione numeri tefticulorum comparatorum cum fuis incifuris. Prima quidem fpecies habet plures incifionis lacinias, pauciores tefticulos. In alterâ verô aequalis eft utrorumque numerus. Sed numerat tertia duplum tefticulorum refpectu fegmentorum. In quartâ denique numerus organorum mafculinorum fuperat adhuc exceffu majore fectas petali Jacinias quam in tertiâ fpecie.

Primae fpeciei flores funt Valerianae, Valerianel E 2 lae, 
de Valerianella, de Blitum, d'Alchimilla, d'Orchis, d'Elleborine ; de Calceolus, de Limodorum, d'Ophris, de Nidus avis, E de plufleurs autres plantes Liliacées.

De la feconde forte, font celles de Rhabarbarum, de. Beta, d'Atriplex, d'Herniaria, de Parietaria, de Polygonum, de Fagopyrum, de Kali, d'Amaranthus $\mathcal{E}^{c}$.

De la troifiéme je ne connois encore que la fleur de Knawel ou d'Alchimilla graminco folio, majori flore $7 . R$. H. 508 .

Enfin entre les fleurs de la quatriéme Ë derniere forte, font furtout les fleurs de Tithymalus.

Il ne faut pas finir, Meffieurs, fans vous faire obferver que lorfgue les fleurs monopetales qui. font accompagnées de l'ovaire, ne font pas des expanfions contimuës de. la peau de leur fupport, elles font toiijours percées. dans Leur fond. Et ficela n'étoit, comment voudroit-on qu'elles. donnafent paffage a cet ovaire on a Jes trompes? On nous. dit pourtant pofitivement, (dans une metbode un peu trop. ventée) que la fleur de l'Androface, n'eft point percée; Et que celles dè la petite Centaurée, du Plantin, de Po-. lygala 'E़ du Cheorrefeüille, font fermées dans leur fond; bien que ces diverfes fleurs foient a calice.

Voila, en général, Méfleurs, l'idée qu'il faut fe for-. mer de la fructure des fleurs, de leurs differences, ED de l'ufage de leurs parties.

Avant que d'en venir a la demonftration dès Genres. jen établirai toijjours le caractere. conformement a la metbode que jaurois déja donnée au public, ainfy que mon Herbier des environs de Paris, $\sqrt{l}$ mon peu de fanté. me l'eît permis. Car de pretendre avec un autbeur. celebre que la pinfpart de ces Genres foient ëtablis foulement par rapport à une fructure bien ou mal entendië des deux fortes de parties dont il s'eft fervi, E a certaines reffemblances qu'il s'eft imaginé quelles ont avec des. chofés conmuës auxquelles il les compare, c'eften verité. Je 
lae, Bliti, Alcbimillae, Orcbidis, Elleborines, Calceoli, Limodori, Ophridis, Nidiavis, plurimarumque aliarum plantarum Liliacearum.

Rbabarbari, Betae, Atriplicis, Herniariae, Parietariae, Polygoni, Fagopyri, Kali, Amas:antbi, Ec. flores ad fecundam pertinent.

Tertiae fpeciei folum florem Knawel, vel Alchimillae. Gramineo folio; flore majore. I. R. Herb. 508. cognofco.

Quartae tandem ultimaeque fpeciei praeprimis funt flores Titbymali.

Finem imponere non eft mihi fas, Auditores, nifi prius vobis obfervandum hoc propofuerim; quod, quando flores monopetali, ovario uniti, non funt nifi ex panfa, continuata, pellis fuperior fui fuftentaculi, femper pertufi inveniuntur in fuo fundo. Quod nifi contigifet, quânam via Pervenire poffent-feminiferi halitus in ovaria vel tubas. Affirmatur nihilominus fatis confidenter, in methodo nimis paululum jactatâ, florem Audrofaces imperforatumeffe, Centaurii autem minoris, plantaginis, polygalae, Caprifolii, flores fundum habere omninô claufum, quamvis omnes hi, tam diverfi flores, calicem habeant.

En, Auditores, ideam, quam habere decet fabricae florum, horum differentiae, ufufque partium, quibus conftant.

Antequam jam progrediar ad demonftranda plantarum genera, prius femper definiam Characterem juxta Leges Methodi, quam jam pridem evulgaffem, ut \& Botanicon meum Lutetianum, fi fluxa mihi id conceffifet mea valetudo. Velle enim ex mente Auctoris Clariffimi, maximam generum partem folidê ftabilitam, idque refpectu fabricae vel benê vel malê intellectae binarum partium, quibus Ille ad hanc rem ufus fuit, \& quarundam convenientiarum quas, comparatione inftitutâ, iis aliis rebus cognitis communes effe, finxit, id verô in re feriâ eft ludere.

$$
\mathrm{E} 3 \mathrm{Ne} \text { - }
$$




\section{8

moquer. Et pour le peu qu'on fuive une methode qui ne roule que fur des principes $f i$ vegues $\xi 5$ fi paffagers, on en eft bientött dégouté.

Aufji ne voit on que quelques brocbeurs de nouveaux genres qui êtant ébloïis de fon riche clinquant, je veux diré, de la beauté $E$ de la multitude de jes figures dont les trois quarts font inutiles; Et perfuadez par les temoignages authentiques de lautheur, que cotte methode eft excellente, qu'il n'eft guere poffibile d'en reduire d'autres en pratique, Et que c'eft la feule qui fe puiffe accommoder a l'ufage; on ne voit disje que ces Mefleurs, qui, pleins de confiance, ofent marcher de pied ferme dans ce champ encore plus beriffé de Ronces \&ु d'Epines, qu'il n'eft furchargé de portraits de fleurs \& de fruits. Eb, qui ne se recriroit pas à l'afpect de toutes leurs meprifes!

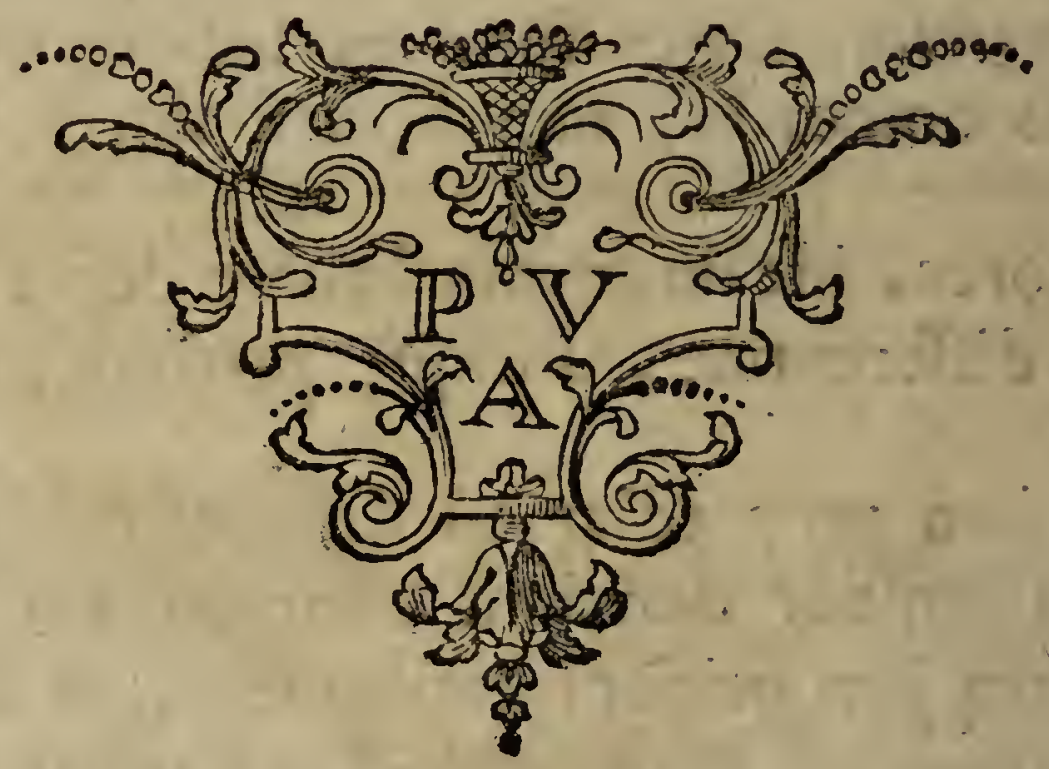


Neque parum quis excolit modô methodum vagis adeô \& caducis fubnixam principiis, quin toediofo ejus faftidio affectum fe experturus fit.

Sed \& cernuntur Textores quidam novorum generum in re herbariâ, quorum perftringit oculos mentemque fulgidus tam divitis orichalci fplendor; pulchritudinem intelligo \& copiam Iconum, quarum fane tres quartae partes funt inutiles. Sed hi credulitatem fuam addicunt proprio Auctoris teftimonio, quo ipfe feverus dictitat: metbodum banc fuam excellentem effe; vixque poffibile baberi aliam invenire ufibuis idoneam; banc verô unicam effe illam, quae ufui apta fut छु bona. Certê haud alios videas, nifi hofce folos, qui confidentiâ inflati, aufint firmo incedere talo per campum Carduis horridum magis fpinifque, quam oneratum nimis \& fruftra florum imaginibus pictis \& fructuum. Quis non obftupefcat ad adfpectum tot tantorumque errorum, quos toties committunt?

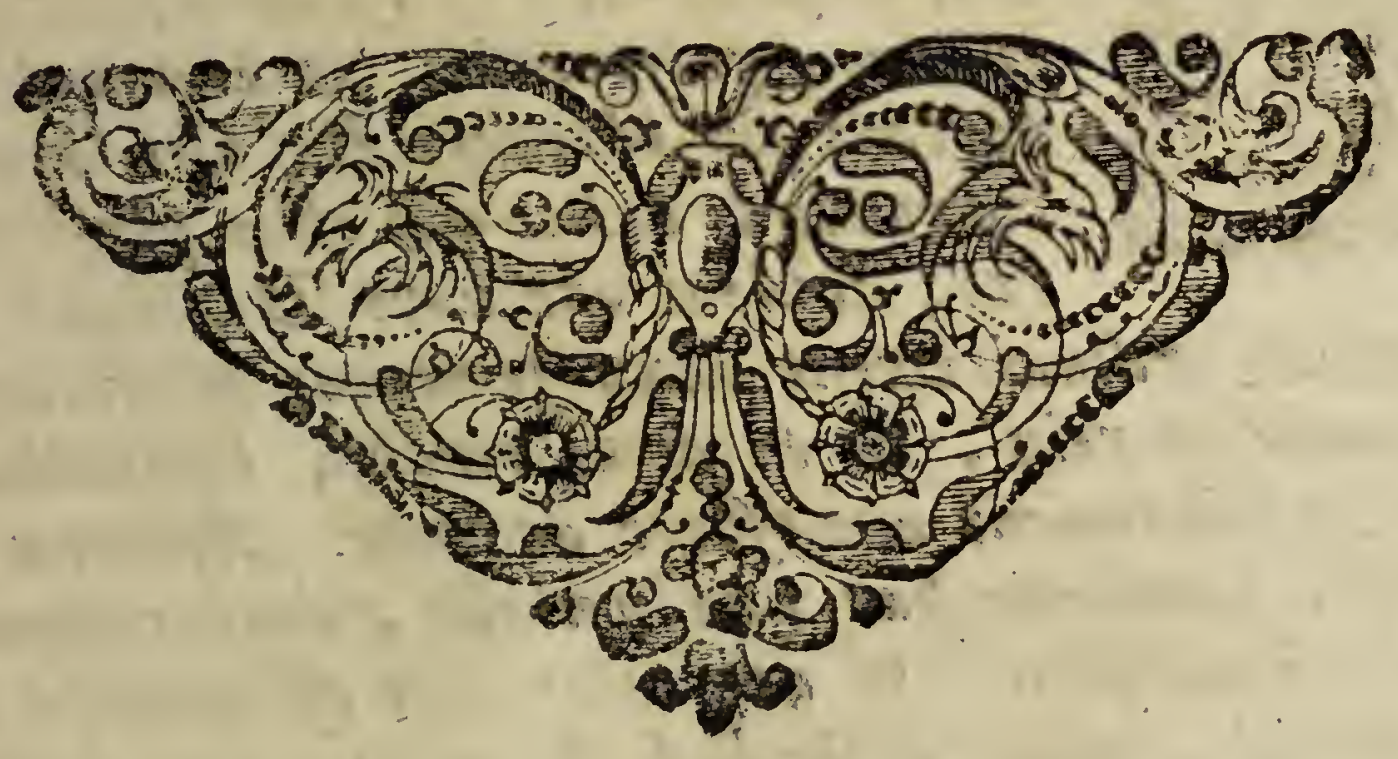




\section{ETABLISSEMENT}

d'un nouveau genre de Plante nommé

\section{A R A I A STRUM,}

duquel le fameux NINZIN ouG INSENG des Chinois, eft une espece.

Communiqué au deuxiéme Janvier I 7 I 8. à Monfieur B OER H A ve Profeffeur en Medecine E๐ Botanique a Leyde,

par S. VAILlant Demon-

frateur des Plantes au Fardin Royal de Paris.

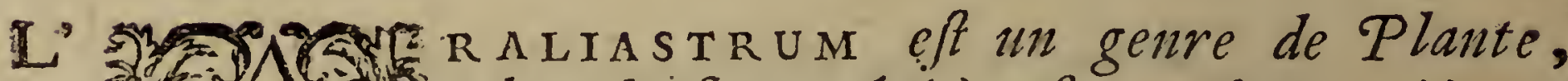
ches la fleur $A\left(^{2}\right)$ eft complette, (b) re- guliere, polypetale, E Hermaphrodite,

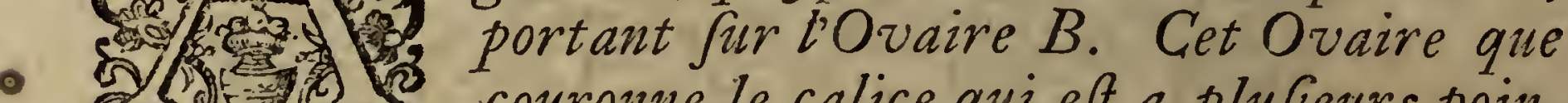
2. couronne le calice qui eft a plufieurs pointes, devient une bave $\mathcal{D}$, dans laquelle se trouvent ordinairement deux-Semences applaties, coupées comme en rein, oil en demi cercle, lefquelles representent conjointement une efpece de caur. Ajoutez, la tige fimple, terminée par une umbelle, dont chaque rayon ne porte qu'une fleur, E़ que cette tige eft accolée au delà de fa moitié, comme celle de l'Anemone, par l'afemblage circulaire des bafes de quelques queviës, du bout de chacune defquelles partent plufieurs feüilles dijpofées en rayons ou en main ouverte.

(a) Voyés Aralia dans les Inftit. I. h. Tab. 154. (b) c'eft a dire, garnie d'un calice. 


\section{O NSTITUTIO}

Novi Plantarum generis, quod nominatur

\section{A R A L I S T RUM,}

Cujus famoja Ninzin aut GIN-seng Chinenfum jpecies eft.

Per literas commmicata datas 2 Fanuarii $\mathrm{I}>\mathrm{I} 8$. ad Hermannum Boerhanve Profefforem Medicinae \&o Botanices Lugduni Batariorum per SEBASTIANUM. VAILLANT Demonftratorem Stirpium in borto Regio Parifirs.

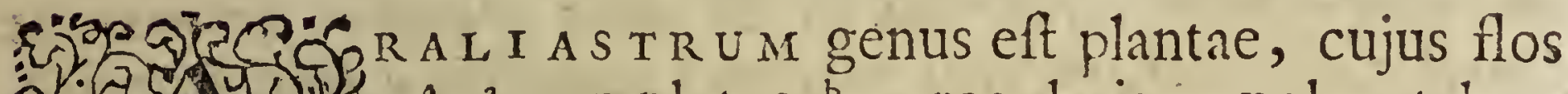
a. If I A completus ${ }^{\mathrm{b}}$, regularis, polypetalus, hermaphroditus innafcitur ovario B. Ovarium hoc, quod calicem multis acuminibus ornatum coronat, fit bacca D, in quâ reperiuntur ut plurimum duo femina compreffa, fecta quafi in renis vel femicirculi formam ita, ut unita fpeciem cordis referant. Adde huic characteri caulem fimplicem, qui in umbellam exit cujuslibet radii extremo unum modo florem gerentem. caulis fupra medium fuae altitudinis inftar Anemones circumcingitur appofitis in orbem bafibus pedunculorum, quorum finguli in extremo fuo gerunt folia plura in radios digefta, aut in fpeciem expanfae manus.

a Vid. Aralia Inft, R. Herb. Tab. I54. 6 Id eft calice donatus. 


\section{E S C R I P T I O N D E}

Les efpeces de ce genre font,

1. Araliaftrum Quinquefolii folio, majus, Ninzin vocatum, D. Sarrazin. Gin-feng. des Lettres édifiantes \& carieufes. Tom. 10. pag. I72.

2. Araliatrum Quinquefoli folio, minus D. Sarrazin. Plantula Marilandica, foliis in fummo cauliculo ternis, quorum unumquodque quinquefariam dividitur, circa maxgines ferratis. $N^{\circ}$. 36. Raij Hift. 3.658.

3. Araliaftrum Fragaria folio, minus. Nafturtium Marianum, Anemones fylvaticæ foliis enneaphyllon, floribus. exiguis Pluk. Mantifs. 135. Tab. 435. fig. 7:

Pour faire connoûtre en quoi l'Arialaftrum differe de l'Aralia (a.) d'ou derive fon nom, il eft a propos de joindre. ici le caractere de ce dernier genre.

L'Aralia (a.) eft tout a fait femblable a l'Araliaftrum par la fructure ES la Jituation de fa fleur, mais Ja baye. contient ordinairement cing femences difpofies en rond autour de fon axe. 'D'ailleurs fes feüilles font brancbuës a: peu prés comme celles de l'Angelique; 'E les tiges qui, dans. quelques efpeces, font nuës, छo dans d'autres garnies de: feïilles alternes, portent plufieurs umbelles a leur fommité. Les especes d'A ralia funt,

1. Aralia caule apbyllo, radice repente D. Sarrazin. Chriftophoriana Virginiana, Zarzae radicibus furculofis, \& fungolis, Sarfaparilla noftratibus dicta Pluk. Almag. 98. Tab. 238. fig. 5. Zarzaparilla Virginienfibus noftratibus dicta, lobatis Umbelliferae foliis Americana. Ejufd. Almag. 396.

2. Aralia caube foliojo, laevi D. Sarrazin. Aralia Canadenfis Inftit. R. H. 300.

3. Aralia caule foliofo, ES bifpido D. Sarrazin.

4. Aralia arborefcens, sinofa. Angelica arborefcens, fpinofa, feu Arbor Indica Fraxini folio, cortice fpinofo. $N^{\circ}$. r. Raij Hift. 2. 1795. Chriłtophoriana arbor aculeata, Virginienfis Pluk. Almag. 98. Tab. 20.

(a.) Des Inftit. v. h. 300. Tab. I54. 


\section{L'A R A L I A S T R U M.}

Species hujus generis habentur.

I. Araliaftrum, Quinquefolii folio; majus, Ninzin vocatum, Di. Sarrafin. Gin-feng. des Lettres édifiantes E़ Curieufes. Tom. 10. pag. I 72.

2. Araliaftrum; Quinquefolii folio; minus Di. Sarrazin. Plantula Marilandica, foliis in fummo cauliculo ternis, quorum unumquodque quinquefariam dividitur, circa margines ferratis. No. 30̂. Raj. Hift. 3.658 .

3. Araliaftrum; Fragariae folio; minus. Nafturtium anemones Sylvaticae foliis Enneapbyllon, floribus exiguis. Plukn. Mantiff. 13.5. Tab. 435. Fig. 7.

Ut intelligatur Araliaftri ab Aralia, a unde nomen fuum derivat, differentia, conveniet \& Characterem pofterioris hujus generis fubnectere.

Aralia Simillima Araliaftro fabricâ, fituque, floris, bacca verô ejus continet ut plurimum quinque femina in orbem axi circumpofita. Caeterum \& foliâ ejus brachiata fere Angelicae inftar; caulefque, qui in quibufdam fpeciebus nudi funt, quique in aliis alternatim pofitis ornantur foliis, omnes ferunt in fuâ fummitate femper umbellas plures.

Araliae fpecies funt.

r. Aralia; caule aphyllo; radicè repente Di. Sarrazin. Cbriftophoriana, Virginiana Zarzae radicibus furculofis E fungofis; Sarfaparilla Noftratibus dicta; Plukn. Almag. 98. Tab. 238. Fig.5. Zarzaparilla Vinginenflbus Noftratibus dicta, lobatis umbelliferae foliis Americana: Plukn. Almag. 396.

2. Aralia; caule foliofo, laevi. Di. Sarrafin. Aralia Caiadenfis. Inft. R. Herb. 300.

3. Aralia; caule foliofo \& Hifpido. Di. Sarrazin.

4. Aralia arborefcens, Spinofa. Angelica arborefcens Spinofa, Sen Arbor Indica fraxini folio cortice Spinofo. No. I. Raj. Hift.2 1795. Chriftopboriana arbor aculeata Virginienfis. Plikn. Almag. 98. Tab. 20.

a Inftit. R. Herb. 300. Tab. I54。 


\section{D E S C R I P T I O N D E}

Toutes les eppeces de ces deux genres, a l'exception de la derniere de l'un EF de lautre, font communes en Canada, d'ou Monfenr Sarrazin Confeilier au Confeil fupericur. Medecin du. Roy EG Correfpondent de l'Academie Royalé des Sciences les a envoyées pour la premiere fois, an Jar din Royal de Paris, des l'année I 700.

Les babitans de la Colonie, Eु cenx de la Virginie, appellent falsepareilice, la premiere espece d'Aralia, parceque fes racines en ont a peu prés la figure Eo les vertus. Monfleur Sarrazin dit avoir traité un malade d'une vomique, lequelpar linfage dine boiffon faite avec ces racines, s'etoit guery dune anajarque, deux ans anparavant. Cet babile Medecin affeîre que les racines de la feconde efpece êtant bien cuites Es appliquées en cataplasme, font tres-bonines pour la guerifon des vieux ulceres, de méme que leur decoction, de laquelle on bafjine \&5 feringue auffi los playes. Il ne doute point que les vertus de la troifiéme quion va décrire brievement", ne foint les mémes que celles de la fécondè a. Ses racines tracent हु pouffent des tiges qui s'slevent ordinairement a la bauteur d'un pied ES demi, ES quelquefois de deux pieds, la partie inferieure de ces Tiges oft berifrée de poils roux, durs E piquants. Elles font accompagnées depuis leur origine jufque vers leur partie fuperieure Ë rameufe par des feuilles alternes, brancbues EG prefque femblables a celles de. Podagraria hirfuta Angelica folio \& odore. Qui eft gravé dans la zde partie du Mufaeum de Boccone, Tab. I9. fous le nom de Cerefolium rugofo. Angelicae folio, aromaticum: Eot dans Rivinus, fors cehi de Myrrhis fol. Podagrariae.

Enfin ces Tiges, Es leurs rameaux, fe terminent par des umbelles fmples, chargées, comme celles des autres efpeces, äes fleurs a cinq petales eganx Es entiers, entourant antant d'étamines; Fo cellescy, un pareil nombre de trom. pes capillaires, qui partent diu fond d'un calice a cinq de.

a. Courte defcription de la' 3 . efpece d'aralia. 
Omnes fpecies binorum horum generum, exceptâ ultimâ utriufque, vulgatae funt in Canadà; unde Vir Clarus, Dominus Sarrazin, in fupremo Confilio Confiliarius, $\mathrm{Me}-$ dicus Regius, Membrumque Academiae regiae fcientiarum mifit primâ vice anno 1700 . in Hortum Regium Parifienfem.

Incolae coloniae, ipfique Virginiae habitatores, appellant primam Araliae fpeciem Salfepareille: quia radices ejus fere figuram virtutemque poffident eandem. Dominus Sarrafin ait fe curaffe vomicâ laborantem aegrum, qui afu liquoris potulenti ex radicibus his confecti fanatus fuit

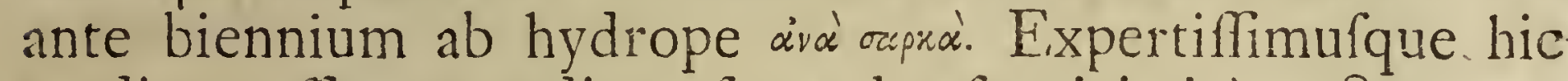
medicus affirmat radices fecundae fpeciei ritè coctas, exhibitafque formâ catapláfmatis optimas haberi curandis inveteratis ulceribus, itemque decoctum etiam illarum, quo vulnera lavant, fovent, aut injiciendo purgant; nec dubitat, quin tertiae fpeciei eaedem. fecundae vires fint. Hanc breviter ita defcribam.

\section{Aralia tertia.}

Radices formant, emittuntque, caules, qui plerumque affurgunt in proceritatem fefquipedis, bipedalem quandoque attingunt. Pars caulium inferior hirfuta pilis rufis, duris, pungentibufque. Sociantur verô caules ab origine ufque in fummitatem ramofam foliis alternê pofitis, brachiatis, fimilibus Podagrariae Hirfutae, Angelicae folio \&s odore. Quae planta cernitur incifa aeri $T^{\prime} b$ b 19. in parte alterâ Mufaei Boccone, fub nomine Cerefolii rugofo Angelicae folio, Aromatici. \& apud Rivinum titulo Myrrbidis. folio podagrariae. Denique caules hi, eorumque rami, exeunt in umbellas fimplices, fuftinentes, ut aliarum fpe: cierum umbellae, flores quinque petalis aequalibus \& integris conftantes, cingentibus totidem ftamina, quae rurfum ambiunt tubas capillares quinque numero, quae quidem tubae exeunt e fundo calicis quinquefidi e diametro op- 


\section{$4^{6}$ DES C R IP T IO N DE}

coupures diametralement oppofé au pedicule de l'ovaire, ow du jenne fruit. Cet ovaire devient enfuite une bave Spherique contenant cinq femences.

Le Ninzin, ou premier Araliaftrum, fe trouve dans les bois fituez fous les 45. Ev 46. degrez de latitude; Ev le fecond fous les 47.

La premiere efpece d'Aralia crôit dans les clarieres des forets fous les 40, 45, छ̈ 47. degrez. La feconde, qui eft conmue dans le pays par le nom d'Anis, en ce que Jes bayes en ont, dit on, le gout, fe rencontre dans de bonnes terres, fous les $40,45, \mathfrak{E}^{6} 50$, degrez; $\mathfrak{G}$ la troifiéme fous les 48.

\section{AUTRE ETABLISSEMENT}

De deux nouveaux genres de Plantes avec la defcription d'un pareil nombre de nouvelles efpeces rapportées a l'un de ces mêmesgenres.

\section{Genre I.}

\section{$S$ H E R A R D I A.}

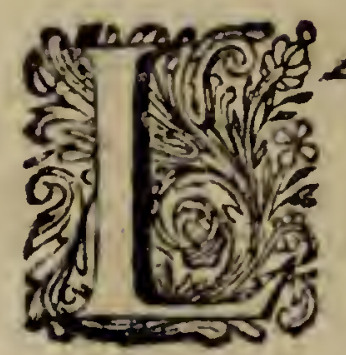

1 Sherardia eft un genre de Plante dont la fleur ne peut étre mieux comparée qu'a celle de la Vervene $\left({ }^{a}\right)$; car outre qu'elle eft complette, monopetale, irreguliere Eु bermapbrodite contenant l'Ovaire, fon pavillon fe decoupe aufji en deux levres inegales: l'une recoupée en deux parties, of l'autre en trois; ou fil l'on vent, il fe partage en cinq lobes, Sçavoir deux fuperieurs, deux lateraux है un inferieur. L'Ovaire qui part du fond du calice dewient aprés que la fleur eft pafée, mue capjule fecbe con-

(a) Voyez les Infit. V. H. Tab. 94. fig. A. 


\section{L'A R A L I A S T R U M:}

pofiti pediculo ovarii, aut fructus junioris. Tandem evadit ovarium hoc in baccam fphaericam continentem femina quinque.

Ninzin, five primum Araliaftrum, reperitur in Sylvis fitis fub latitudine graduum 45,46 . Secundum verô in latitudine 47 . graduum.

Prima Aralia crefcit in campis inter nemora fitis fub latitudine $40,45,47$, graduum. Altera, quae titulo Anifi cognofcitur apud indigenas loci, quia baccae ejus feruntur faporem ejus referre, in folo cref́cit fertili : fub latitudine $40,45, \& 50$. graduum; tertia tandem fub 48 . gradibus.

\section{ALTERA CONSTITUTIO}

Duorum novorum generum Plantarum, unâ cum defcriptione binarum specierum novarum, ad inum borim generim relatarum.

\section{Genus I. \\ S H E R A R D I A.}

ggeaer HER A R D A eft genus Plantae, cujus flos nequit ( 10 melius comparari quam flori verbenae $\left({ }^{2}\right)$ : pra-

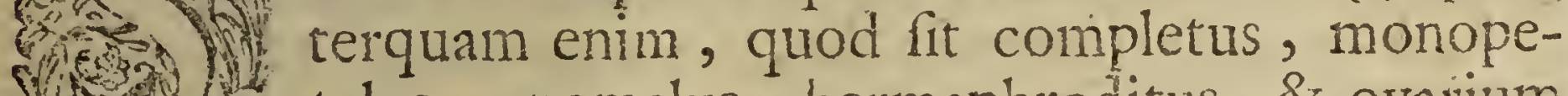
talus, anomalus, hermaphroditus, \& ovarium complectens, expanfa ejus margo etiam finditur in labia bina inaequalia, quorum unum in duas fecatur partes, alterum in tres; aut, fivelis, dividitur in lobos quinque, binos fcilicet fuperiores, laterales duos, unumque inferiorem. Ovarium ex fundo calicis affurgens, fiore de-

(a) Vid. Inftit, R. H. Tab. 94. Fig. A.

lapfo, 


\section{D E S C R I P T I O N DE D E U X}

tenant deux femences. Les feïilles font fimples E oppoJées, Ë les fleurs difposées en épi.

\section{Les eppeces de ce genre font,}

x. Sherardia repens, nodiftora. Verbena nodiflora J. B. 3. lib. 30. p. 444 . C. B. Pin. 269.

2. Sherardia repens, folio fubrotundo crafso, nodiflora. Anacoluppa Hort. Malab. 1o p. 93. Raij Hift. 3. 316. $\mathrm{N}^{\circ}$. 30.

3. Sherardia incana, nodiflora. Verbena nodiflora, incana, Curaffavica, latifolia Par. Bat. Prod. 383 . Raij Hift. 3. 286. Pluk. Almag. 382. Tab. 232. fig. 4 .

4. Sherardia nodiflora, Stoechadis Jerrati folii folio. Lavandula foliis crenatis, latioribus, Americana; frutefcens Plum. Cat. 6. Inftit. R.H. r98. Verbena nodiflora Curaffavica, foliis Menthae Par. Bat. Prod. 383. Raij Hift. 3.287. 5. Sherardia Ocymi folio, lanuginofo, flore purpureo. Verbena Americana, media, annua, Ocimi folio lanuginofo, flore purpureo amplo Breyn. Prod. 2. Raij Hift. 3.285. Verbena Scutellariae S. Caffidae folio difpermos, Americana Pluk. Almag. 382.Tab. 70. fig. x.

6. Sherardia Teucrii folio, flore purpureo. Verbena fpicata Jamaicana, Teucrii pratenfis folio, difpermos Raij Hift. 3. 285. Pluk. Almag. 382. Tah. 32r. fig. r.

7. Sherardia frutefcens, Teucrii folio, flore caeruleopurpurafcente amplifimo. Verbena Americana, frutefcens Teucrii foliis, fioribus caeruleopurpurafcentibus amplifimis Breyn. Prod. 2. Raij Hift. 3. 285 . Verbena Orubica Teucrii folio, Primulae veris flore, filiquis \& feminibus longiffimis Par. Bat.Prod. 383 . Pluk. Almag. 382.Tab. 327. fig. 7.

8. Sherardia Teucrii folio, flore coccineo. Verbena Americana, Veronicae foliis flore coccineo fpicato Breynii Hort. Amitel. 2. 223. Raij Hift. 3. 28.6.

Comme ce renre doit être rapporté immediatement auprés de la V́rvéne $\left({ }^{2}\right)$, laquelle n'en differe à properement parler, que par to nombre de fes fomences qui eft de quatre, on auroit peit le nommer Verbenaftrum; mais (a) Verbena. 


\section{NOUVEAUX GENRES DE PLANTES.}

lapfo, fit capfula ficca, continens duo femina. Folia funt fimplicia, oppofita, flores in fpicam digefti.

Species hujus generis funt.

r. Sherardia; repens, nodiflora. Verbena nodiftora $\%$. B. 3. lib. 30. p. 444.C. B. Pin. 269.

2. Sherardia repens, folio fubrotundo craffo, nodiflora. Anacoluppa Hort. Malab. 10.p. 93. Raij Hift. 3. 3 I6. No. 30.

3. Sherardia incana, nodiflora. Verbena nodiflora, incana Curaflavica, latifolia Par. Bat. Prod. 383 . Raij Hift. 3. 286. Pluk. Almag. 382. Tab. 232. fig. 4.

4. Sherardia nodiflora, Stoechadis ferrati folii folio. Lavandula foliis crenat is latioribus, Americana, frutescens. Plum. Cat. 6. Inftit. R. H. I98. Verbena nodifora Curafsavica, foliis Menthae. Par. Bat. Prod. 383 . Raij Hift. 3.287.

5. Sherardia Ocymi folio, lanuginofo, flore purpureo. Verbena Americana, media, annua, Ocymi folio lanuginoso, flore purpureo amplo. Breyn. Prod. 2. Raij Hift. 3. 285. Verberia, Scutellariae, five Ciafidae folio, dispermos, Americana. Pluk. Almag. 382. Tab. 70. fig. I.

6. Sherardia Teucrii folio, flore purpureo. Verbena fpicata Zamaicana, Teucrii praten/s folio, dispermos. Raij Hijt. 3. 285. Pluk. Almag. 382. Tab. 321. fig. I.

7. Sherardia frutefcens Teucrii folio, flore caeruleo purpurafcente amplifimo. Verbena Americana, frutefcens Teucrii foliis, floribus caeruleo purpurafcentibus ampliffimis. Breyn. Prod. 2. Raij Hift. 3.285. Verbena Orubica Teucrii folio, Primulae veris flore, Siliquis है Semimibus Longifjimis. Par. Bat. Prod. 383 . Pluk. Almag. 382. Tab. 327. Fig. 7 .

8. Sherardia Teucrii folio, flore coccineo. Verbena Americana, Veronicae foliis, flore coccineo jpicato Breynii Hort. Amft. 2. 223. Raij Hiff. 3. 286.

Quum lege difciplinae genus hoc ftatim referendum fit poft Verbenam, quae inde non differt reverâ, nifi folo feminum numero fuorum, quae Verbenae quatuor nafcuntur, potuiffet appellari ideô Verbenaffrum. Verum quum G BO- 
les Botaniftes eftant en droit de pouvoir exprimer les nouveaux genres ou par les noms de leurs Autbeurs, ou par ceux de leurs bienfaidtcurs E de leurs amis, pour reffufoiter les uns EG immortalifer les autres dans la Botanique, j'ai impofé a celuy-cy le nom de l'Illuftre Mr. Sherard qui eft tour à la fois, EG mon veritable Ami, E़ mon bienfaicteur en fait de Plantes fecbes, EG a qui ib nerefte plus pour eftre efimé autant que tous les Autbeurs cufemble, quia finir fon Pinax Eु a le donner au public qui attend de lui ce chef-d'oeuvre, avec la derniere impatience.

La Sherardia Ė la Vervéne quieft comprife mal à propos entre les plantes de la quatriéme Clafe des Inftitutions de Botanique, doivent entrer dans la troifiéme E़ y precader l'Adhatoda.

\section{Genre II.}

\section{B O E R A A V I A.}

T a Boerhaavia 'eft un genre de Plante dont la fleur eft 1 complette, reguliere, monopetale, pentagone, EF bermapbrodite portant fur l'ovaire, dains la couronne duquel elle s'articule. Cet ovaire devient une capfule monolperme, conique ou pyriforme, feche, folide E़ canelée felon. Ja longuarur. Les feuilles font fimples Eg oppolées par paires le long des iziges, avec cette circonfance quine des feuilles de chaque paire oft ordinairement plus grande que l'autre. Les efpeces de ce genre font,

I. Boerbacwa Solanifulia, major. Valerianella Coraffavica, femine afpero, viscofo Par. Bat. 2.37. Piuk. Tab. II3. fig. 7. Valerianclla folio fubrotundo, flore purpureo, femine oblongo, ftriato, afpero Car. Jam. 9r. Raij Hift. 3.244. Valeriana humilis, folio rotundo fubtus argenteo Plum. Cat. 3. Talu-Dama Hort. Malab. 7. I05.

2. Bnerbaavia Nubica, minor.

3. Boerbaavia Nubica, minima. 


\section{NOUVEAUX GENRES DE PLANTES.}

Botanicis jus datum fit, ut queant exprimere nova genera aut Auctorum iis nomen imponendo, aut \& Eorum, à Quibus accepere benefacta, vel cum Quibus amicitiam excoluere; ad excitanda illa, hanc verô immortalitati confecrandam, ego huic generi nomen dedi ab Illuftri Gulielmo Sherard, qui fimul \& fincerus mihi amicus, atque etiam refpectu plantarum exficcatarum benefactor verus. Sané hic vir, hic eft, quem tanti feceris unum, quanti caeteros omnes fimul Auctores rei Herbariae, fimulac abfolverit Pinacem Sherardianum, ejufque in publicum evulgatione obftrictam fibi reddiderit Rempublicam Botanicam, quae opus hoc incomparabile ardentifinis ab eo votis exfpectat, flagitatque.

Sherardia \& Verbena, malè locatae inter ftirpes quartae claffis inftitut. R.H. debent tertiae accenferiftatim ante $A$ dbatodam.

\section{Genus II. \\ B O E R H A A V I A.}

Doerbaavia eft genus Plantae, cujus flos completus, regu13 laris, monopetalus, pentagonus, hermaphroditus, ovario infiftens, intra cujus coronam inarticulatur. Ovarium hoc fit capfula monofpermos, conica, aut pyro fimilis, ficca, folida, fulcata juxta longitudinem. Folia huic fimplicia, oppofita per paria fecundum caulium proceritatem eâ lege, ut unum cujufque paris folium altero fit plerumque majus.

Species hujus generis funt.

I. Boerhaavia folanifolia, major. Valerianella Curaffavica, Semine aspero, vijcofo. Par. Bat.237. Phukn. Tab. I I3. Fig. I. Valierianella folio fubrotundo, flore purpureo, femino oblongo, friato, afpero. Cat. Fam.91. Raj. Hift. 3. 244. $V$ aleriana bumilis, folio rotundo jubtus argenteo.Plum. Cat. 3. Talu. Dama. Hort. Maláb. 7. 105.

2. Boerhavia Nubica, minor.

3. Boerhavia Nubica, minima. 


\section{DESCR IPTIONDEDEUX}

La Boerhaavia differe de la Mache ( $\left.{ }^{2}\right)$ Sous laquelle phisCieurs Autbeurs ont reduit la premiere de ces trois efpeces, non feulement par l'inegalité qui fe rencontre dans' les feïil. les d'une même paire ; mais encore par la regularité de la fleur, celle de la Mache êtant effentiellement irreguliére. Ainfi c'eft a tort que M. de Tournefort a compris ce dernier genre dans la feconde Clafje de Jes Elemens छ̋ de fes inftitutions de Botanique, puirque, fuivant fon Syfteme a lia lettre, la Mache appartient de droit a la troifiéme Claffe, on il auroit aufs deit renfermer la Valeriane $\left({ }^{b}\right)$, la Fufquiame $\left({ }^{\circ}\right)$, laVeronique $\left({ }^{\mathrm{d}}\right)$, le Boïillon blanc $\left({ }^{\circ}\right)$, \&' l'Herbe aux mites $\left({ }^{\mathrm{f}}\right)$, d'autant que leurs fleurs font anomales ou irregulieres.

Ce genre auquel on auroit peî donner le nom de Valerianoides, porte celui du celebre $M$. Boerbaave un des plus Sçavans Proferfeurs en Medecine ES en Botanique qui ayent jamais été à Leyde.

La Boerhaavia Nubica, minor, eft une berbe dont. les tiges fout trainantes, tendres, pleines de fuc, longues d'environ un pied fur une ligne dépaiffeur, relevées de plufleurs nseuds diftants l'un de l'autre d'un ponce ou deux. De cbaque nend partent deux feïilles, fimples, entiéres, d'inegale grandeur, de la forme de celles de la Bete. (B), un peu ondées fur lenirs bords, blanchâtres $\xi$ legerement cotonées en defous ou beurs nervelires ont affez de relief. Le deffus de ces feïilles eft d'un vert rejoüifjant, tracé de veines pourpres \&̋ foüetté de la méme couleur en certains endroits. Les plus amples n'ont guere qu'un demi pouce de longueur fur un peu moins de largeur. Il ejt a remarquer que jamais deux grandes ni deux petites feüilles ne fe fuivent immediatement fur un méme côté de la tige, mais que les unes $\mathfrak{G}$ les autres y font toîjours entre meflées alternativement \&ु qu'il en eft ainf des branches dont les plus fortes fortent de l'aiffelle des phus petites feüilles. Ces. branches; ou d'autres feïitles gardent le méme ordre, font terminées par des bouquets de
(a) Valerianella.
(b) Valeriana.
(c) Hyojcyamus.
(d) Veronica.
(c) Verbafcum.

(f) Bhtitaria. (g) Boto. 
Boerbaavia differt à Valerianellâ, fub quam plurimi Auctores redegerunt primam harum trium fpecierum, non modô inaequalitate, quae occurrit in ejus foliis quae per paria conjunguntur, fed \& analogia floris, qui in Valerianellâ naturaliter anomalus. Eft itaque contra leges herbarias, quod Clarus Tournefort comprehenderit ultimum hoc genus fub claffe fecundâ Elementorum \& Inftitutionum rei herbariae: quia juxta fenfum Syltematis ejus Valerianella jure pertinet ad claffem tertiam, cui \& inclufiffe oportuerat quoque Valerianam, Hyofcyamum, Veronicam, Verbafcum, Blattariam, quatenus flores harum omnium anomali funt vel irregulares.

Genus hoc, cui nomen dari potuerat Valerianoidi, appellationem habet a celeberrimo Boerhaave, Profeffore Medicinae \& Botanices in Academiâ Lugduno Batavâ.

Boerbaavia Nubica minor, eft herba, cujus cauliculi repentes, tenelli, fucculenti, pedem circiter longi, lineam craffi, affurgentes in plures nodos qui a fe invicem diftant unum, binofve pollices. oriuntur ex unoquoque nodo folia duo, fimplicia, integra, inaequalis magnitudinis, formầ Betae, parum undulata in margine, candefcentia \& leviter lanuginofa in fuperficie pronâ ubi \& in nervofam Scabritiem afpera Spectantur fatis; in fupinâ verô fuperficie funt laete virentia, venis purpurafcentibus picta, \& hinc inde eodem colore variegata. Maxima horum vix longiora femipollice, paulôque minus lata funt. Notabile videtur, nunquam duo folia magna vel duo parva fe invicem fequi ab uno eodemque caulium latere; fed quod majora femper minoribus alternâ viciffitudine interpolentur, quodque lex eadem obtineat in ramis, quorum fortiffimi femper ex alis minimorum foliolorum exoriuntur. Rami hi, quorum folia eandem denuô fervant ordinem, exeunt in thyrfos florum coloris floris lini dilutioris, fed adeô minutorum, ut vix dimidiatam habeant lineam in diametro ubi expanfi funt. Cuilibet flo- 


\section{4 \\ DESCR I P T I O N DE D E U X}

fleurs gris de lin tendre, mais s petites qu' a peine ont-elles demie ligne de diametre lor fquielles font épanoüies. Chaque fleur eft, pour ainfi dire, un grelot d'une foule piece pliffée a cinq pans Ė decoupée en étoile ou en cing lobes egaux legerement écbancrez par le bout, elle couronne l'ovaire ou la téte de l'embryon du fruit, fur laquelle, an deffaut d'uncalice à decoupures, ou fuffifamment creux pour la pourvoir affijetir, elle eft affermie par la trompe qui la perce ES l'enfile en s'engageant en même tems, comme dans une gaine, entre trois étamines fort courtes EF a fommets jannes, lefquelles s'elevent du fond verdâtre de cette fleur. L'Ovaire qui ne contient quiune feule femence, devient une capfule taillée en forme de cone renverfé dont la bafe eft un peu convexe: Cette capfule eft canelée d'un bout a l'autre, parfemée d'un duvet fort leger, F̋ enduite d'une petite ghu qui s'attache aux doigts. Dans fa parfaite maturité, Sa longueur n'excede pas deux lignes pour l'ordinaire, E̋ fon diametre n'en a pas tout à fait une dans le phus fort de fon épaiffeur. Cette Plante étant machée, n'a que le gouit diberbe, Ef fon fuc ne rougit le Papier bleu que foiblement.

La Boerhaavia Nubica, minima, ne differe de la precedente qu'en ce qu'elle eft beaucoup plus petite dans toutes fes parties; les tiges n'ayant qu'un quart de ligne d'épaiffeur fur trois pouces de longueur. Dans ce dernier Jens, fes plus grandes feïllles n'ont qu'environ quatre lignes, हु feulement deux de largeur ; leur pointe êtant d'ailleur's plus aiguë à proportion que celle des feüilles de la Boerhaavia Nubica minor.

Ces deux Plantes naifent entre Mocbo \&ु Tangos dans la Nubie, ou elles ont été obfervées par feu Mr. Lippi Modecin de la Faculté de Paris, lequel avoit été deputé par Mr. Fagon Confeiller d'Etat ordinaire, premier Medecin du Roy Lou is XIV. Fur Intendant du Fardin Royal Eु bonoraire de l'Academie des Sciences, pour accompagner Mr. du Roule envoyé de la Cour de France en celle d'Etiopie, Fo travailler, en chemin faifant, a l'bifloire naturelle, dans laquelle il êtoit fort J̧̧avant.

$$
\text { F I N. }
$$


rum refert, ut ita dicam; parvam campanulam, ex unô petalo, plicatam in quinque angulos, \& fectam in ftellam, aut in quinque lobulos aequales leviffimê emarginatis apicibus donatos, coronat ovarium vel caput embryonis fructus, fupra quod (defectu calicis incifi aut fatis excavati ut exceptum florem firmare quent) affigitur probofcide, quae florem perforat, eique fe immittit infinuando fe fimul ut in vaginam, intra tria ftamina valde brevia, apiculifque flavis inftructa quae affurgunt ex viridefcente hujus floris fundo. Ovarium, uno modô femine foetum, capfula fit fecta in fpeciem coni inverfi, cujus bafis parum convexa emergit; eft porrô haec ipfa capfula fulcata ab uno in alterum extremo, tenui refperfa tomento, atque glutine pauco digitis adhaerente obducta. Perfectâ maturitate, longitudo frequentiffimê haud excedit binas lineas, ejufdemque diameter, ubi craffifima habetur, vix lineae Iongitudinem affequitur. Manducata haec planta herbofum modô Saporem exhibet, ejufdemque fuccus chartae caeruleae colorem rubrum vix conciliat nifi languidum.

Boerbaavia Nubica, minima, a praecedenti haud differt, nifi quod omni parte fit longê minor; caulibus ejus vix quartam lineae partem craffis, tres autem pollices modô longis. Quâ ratione maxima ejus folia circiter quatuor tantum lineas longa, duafque modô lata funt; apice caeterum acutiore proportionaliter, quam apex foliorum in Boerbaaviấ Nubicâ minore.

Crefcunt ambae polteriores plantae in Nubiâ inter Mocho \& Tangos, ubi obfervatae funt per Clarum Lippi, e Parifinâ facultate medicâ Doctorem, qui legatus ex mandato Nobiliffimi, Ampliffimique Fagon, Ordinarii Confiliarii Status, Archiatri Sereniffimi Regis Ludovici XIV, Summi Directoris Horti Regii Parifini, Profefforifque in Academiâ Regià Scientiarum honorarii, ut comitaretur Dominum Du Roule legatum aulae Gallicae ad AEthiopicam aulam, utque in hoc itinere operam daret hiftoriae naturali, cujus fanê erat peritiffimus. 
Excufo jam libello, accidit, ut nactus aliud exenplay putaverin, hine inde quaedam addi, mutari paululum, aut corrigi ita poffe.

Dans le titre, lign.15. aprés defcription, ajoutez d'un pareil nombre dé nouvelles espeses, \& cffacez de desix nouvelles PL A N T E rapportées au dernier genre, In Titulo, lin. Is. poft defcriptione adde rotidem novarum fpecierum dele duarum P L A N T A R U M novarum generi poffremo infcriptarum, p. 3. !. 2.2.1. wiftatamque 6.7.1. 5. 1.adbuc p. 8.1.9.1. faifte 1. 17. 1. aiguillonnant 1.32. 1. marqués p. 10. 1.21. 1.de p. 14.1.14.1. conns 1.21. 1. renfermée p. 18.1. 5. 1. bafe 1. 11. qu'ill. qu'il les 1.36. 1. Parifiacum L, I. I. p. 19.

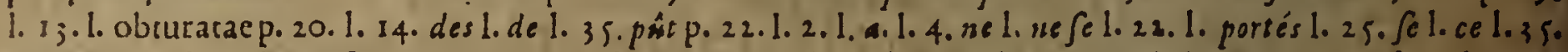

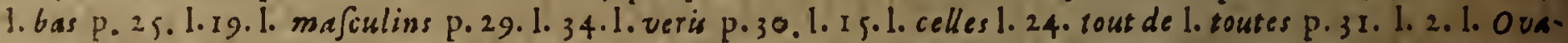
rium p. 32.1.2.1. fruit 1.29. 1. premsieres p. 33.1.22. 1. 1'Ac. p. 34.1. 14. aprés Ruta, ajoutez de Pyrola, 1. 16. aprés toibtes ajoutez les $\mathrm{p} .36 .1$. 32 e établis feulement par rapport à l. folidement établis par rapport foule. ment à p. 42.1. 5. 1. quinquefolii 1.22.1. Sont 1. 36. 1. r. p. 43.1. 3. \$ 29.1. Sarrafin 1.8. 30. 1. 36. 1. g.a.

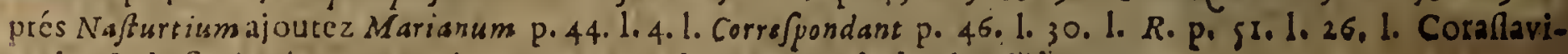

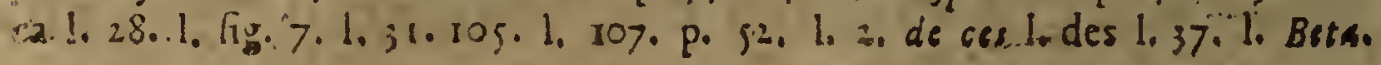

